\title{
Observing Deep Convection in the Labrador Sea during Winter 1994/95
}

\author{
Jonathan M. Lilly,* Peter B. Rhines,* Martin Visbeck, ${ }^{+}$Russ Davis,\# John R. N. Lazier, @ \\ Friedrich SCHOTT, \& AND DAVID FARMER** \\ * University of Washington, Seattle, Washington \\ + Lamont-Doherty Earth Observatory, Palisades, New York \\ \# Scripps Institution of Oceanography, La Jolla, California \\ @ Bedford Institute of Oceanography, Dartmouth, Nova Scotia, Canada \\ $\&$ Institut für Meereskunde, Kiel, Germany \\ ** Institute of Ocean Science, Sydney, British Columbia, Canada
}

(Manuscript received 17 November 1997, in final form 15 July 1998)

\section{ABSTRACT}

\begin{abstract}
A 12-month mooring record (May 1994-June 1995), together with accompanying PALACE float data, is used to describe an annual cycle of deep convection and restratification in the Labrador Sea. The mooring is located at $56.75^{\circ} \mathrm{N}, 52.5^{\circ} \mathrm{W}$, near the former site of Ocean Weather Station Bravo, in water of $\sim 3500 \mathrm{~m}$ depth. This is a pilot experiment for climate monitoring, and also for studies of deep-convection dynamics. Mooring measurements include temperature $(T)$, salinity $(S)$, horizontal and vertical velocity, and acoustic measurement of surface winds. The floats made weekly temperature-salinity profiles between their drift level (near $1500 \mathrm{~m}$ ) and the surface.

With moderately strong cooling to the atmosphere ( $\sim 300 \mathrm{~W} \mathrm{~m}^{-2}$ averaged from November to March), wintertime convection penetrated from the surface to about $1750 \mathrm{~m}$, overcoming the stabilizing effect of upperocean low-salinity water. The water column restratifies rapidly after brief vertical homogenization (in potential density, salinity, and potential temperature). Both the rapid restratification and the energetic high-frequency variations of $T$ and $S$ observed at the mooring are suggestive of a convection depth that varies greatly with location. Lateral variations in $T$ and $S$ exist down to very small scales, and these remnants of convection decay (with $e$-folding time $\sim 170$ day) after convection ceases. Lateral variability at the scale of $100 \mathrm{~km}$ is verified by PALACE profiles. The Eulerian mooring effectively samples the convection in a mesoscale region of ocean as eddies sweep past it; the Lagrangian PALACE floats are complementary in sampling the geography of deep convection more widely. This laterally variable convection leaves the water column with significant vertical gradients most of the year. Convection followed by lateral mixing gives vertical salinity profiles the (misleading) appearance that a one-dimensional diffusive process is fluxing freshwater downward.

During spring, summer, and fall the salinity, temperature, and buoyancy rise steadily with time throughout most of the water column. This is likely the result of mixing with the encircling boundary currents, compensating for the escape of Labrador Sea Water from the region. Low-salinity water mixes into the gyre only near the surface.

The water-column heat balance is in satisfactory agreement with meteorological assimilation models. Directly observed subsurface calorimetry may be the more reliable indication of the annual-mean air-sea heat flux. Acoustic instrumentation on the mooring gave a surprisingly good time series of the vector surface wind.

The three-dimensional velocity field consists of convective plumes of width $\sim 200$ to $1000 \mathrm{~m}$, vertical velocities of 2 to $8 \mathrm{~cm} \mathrm{~s}^{-1}$, and Rossby numbers of order unity, embedded in stronger $\left(\sim 20 \mathrm{~cm} \mathrm{~s}^{-1}\right)$ lateral currents associated with mesoscale eddies. Horizontal currents with timescales of several days to several months are strongly barotropic. They are suddenly energized as convection reaches great depth in early March, and develop toward a barotropic state, as also seen in models of convectively driven geostrophic turbulence in a weakly stratified, high-latitude ocean. Currents decay through the summer and autumn, apart from some persistent isolated eddies. These coherent, isolated, cold anticyclones carry cores of pure convected water long after the end of winter.

Boundary currents nearby interact with the Labrador Sea gyre and provide an additional source of eddies in the interior Labrador Sea. An earlier study of the pulsation of the boundary currents is supported by observations of sudden ejection of floats from the central gyre into the boundary currents (and sudden ingestion of boundary current floats into the gyre interior), in what may be a mechanism for exchange between Labrador Sea Water and the World Ocean.
\end{abstract}

\section{Introduction}

The Labrador Sea is the site of some of the deepest convection in the world ocean (Lazier 1980; Clarke and

Corresponding author address: Dr. Peter B. Rhines, School of Oceanography, University of Washington, Box 357940, Seattle, WA 98195-7940.

E-mail: rhines@ocean.washington.edu
Gascaard 1983). A harsh climate persists over the basin during winter, with westerly and northerly winds bringing cold air from Canada and the Arctic (Fig. 1). Air temperatures at nearby Iqaluit (formerly Frobisher Bay, north of Hudson Strait) can average colder than $-30^{\circ} \mathrm{C}$ for a winter month, when northerly and northwesterly winds can average $6 \mathrm{~m} \mathrm{~s}^{-1}$. Seaward of the continental shelf the sea is held ice free by the inflow of warm, saline waters from the subtropics. This collision of cold 


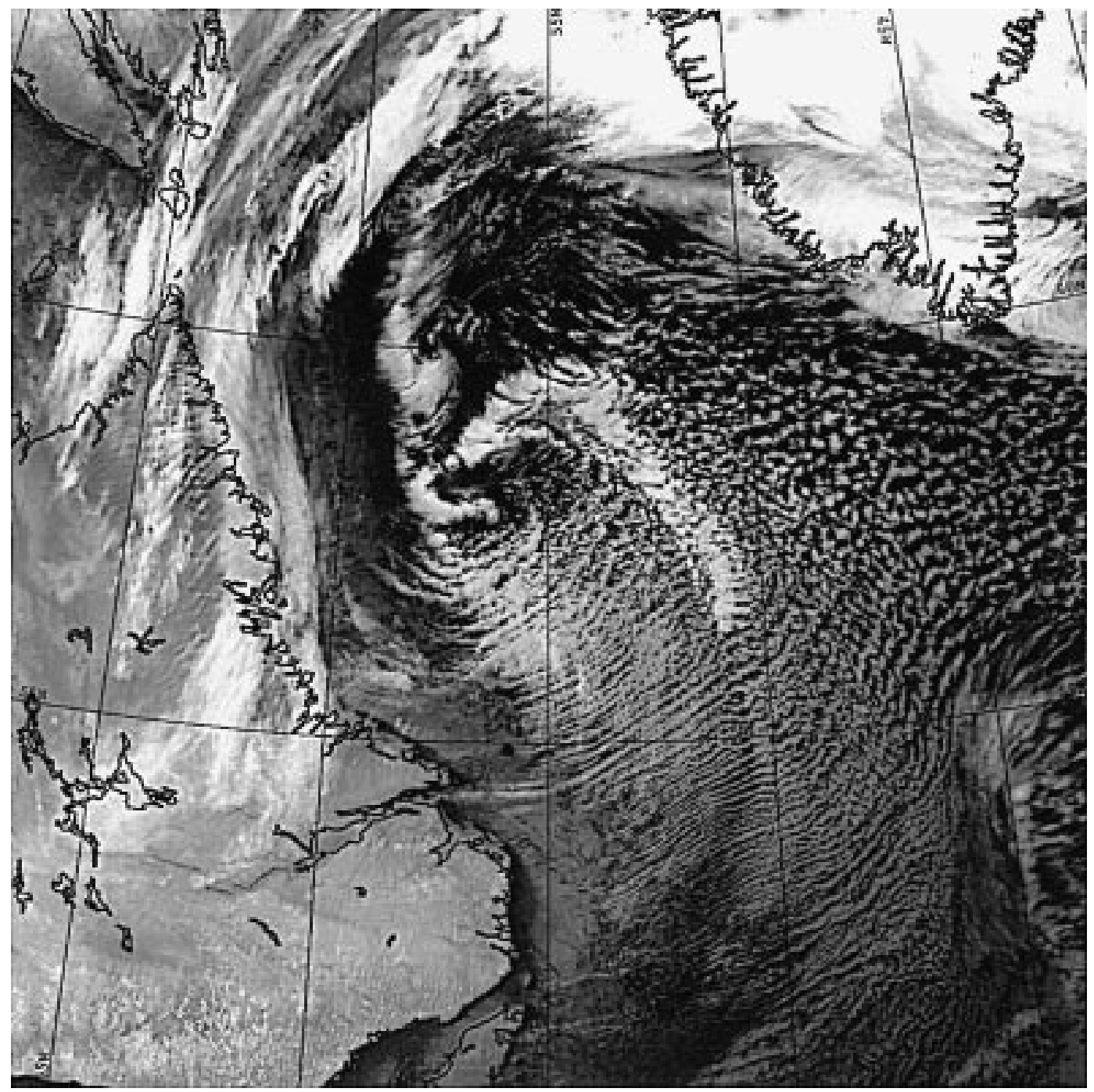

FIG. 1. NOAA AVHRR image of a westerly wind outbreak over the Labrador Sea on 31 Jan 1997 (provided by G. W. K. Moore, personal communication, 1997). Intense convective rolls, indicating upward heat flux at the sea surface, are visible in the lower atmosphere as air flows off the ice-covered Labrador Shelf.

air and ice-free ocean leads to large upward heat flux, reaching $700 \mathrm{~W} \mathrm{~m}^{-2}$ or more (Moore 1996, manuscript submitted to J. Climate), with monthly averages in the range $200-300 \mathrm{~W} \mathrm{~m}^{-2}$. The mean wind in the midLabrador Sea appears to run down its NW-SE axis, in response to the high topography of Greenland. The speed of averaged wintertime winds during December through February ranges from 6 to $10 \mathrm{~m} \mathrm{~s}^{-1}$ in the more severe $50 \%$ of winters and can reach $18 \mathrm{~m} \mathrm{~s}^{-1}$ in individual monthly averages (K. Drinkwater 1997, personal communication).

The large-scale regional ocean circulation is dominated by a cyclonic circulation, the western extremity of the cyclonic subpolar gyre of the North Atlantic (e.g., Lazier 1973; Ivers 1975). Combined wind and buoyancy forcing uplifts isopycnals in the central Labrador Sea, reducing the stratification and making the central waters susceptible to repeated deep convection. This dome of weakly stratified Labrador Sea Water (LSW) presently fills a region $500 \mathrm{~km}$ by $600 \mathrm{~km}$ by $2.3 \mathrm{~km}$ deep (Fig. 2 ), apparently trapped by its encircling boundary currents. The isopycnal plot of salinity on the $27.72 \sigma_{0}$ surface shows conditions in 1965-67 when atmospheric forcing was extremely mild. Cyclonic circulation of boundary currents around the low-salinity core involves large salinity variations along the apparent direction of flow; these are shown by Rhines and Lazier (1995) to coincide with seasonal pulsation of boundary current transport (as inferred from a current meter mooring on the continental slope) and most likely in the transport of LSW out of the Labrador sea. In this figure the saline Irminger boundary current is interrupted near Hamilton Bank, Labrador $\left(55^{\circ} \mathrm{N}, 54^{\circ} \mathrm{W}\right)$, where much lower salinity characteristic of central LSW appears abruptly. 


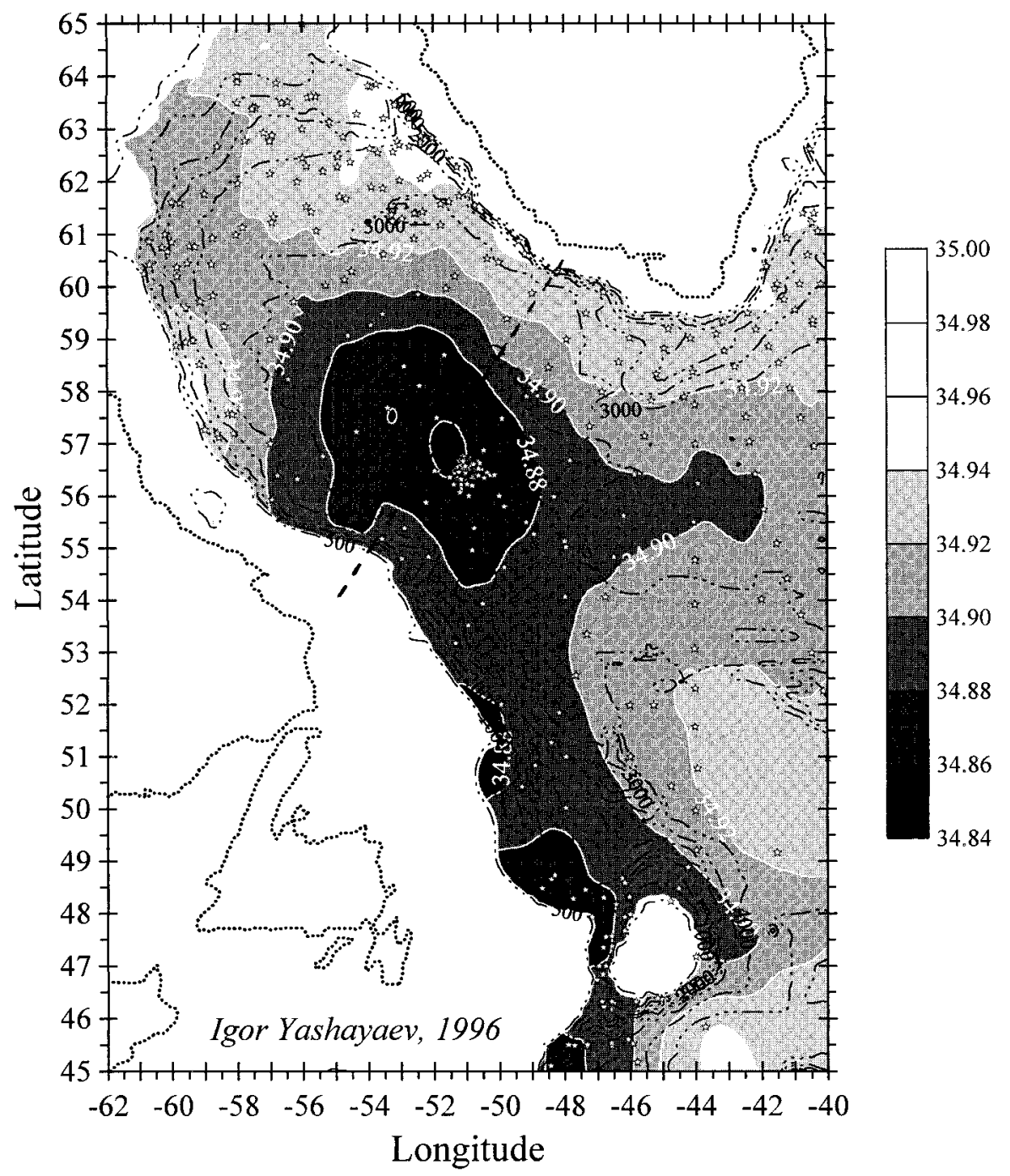

FIG. 2. Map of Labrador Sea region together with salinity on $\sigma_{0}=27.72 \mathrm{~g} \mathrm{~kg}^{-1}$ isopycnal during 1965-67 (Yashayaev 1996). This isopycnal was typically $500 \mathrm{~m}$ deep near the central salinity minimum, descending to about 1-km depth at the boundary. The southeastward flowing boundary current at the Labrador continental slope appears to be transporting low-salinity water out of the Sea, while high salinity water, enters round Cape Farewell, Greenland. (Rhines et al. 1998).

The low salinity extension of the LSW southeastward along the continental slope has been documented recently by Pickart et al. (1996) and by Pickart et al. (1997) and suggests comparison with the models of Hallberg and Rhines (1996) in which convected waters encountering the sloping boundary are carried off equatorward.

There is substantial variation of wintertime convection at interannual timescales and longer. Dickson et al. (1996) and Rhines (1994) document this variability and its connection with the North Atlantic Oscillation (NAO) of the atmosphere. The low-frequency variation of the Icelandic low pressure center contributed to the particularly mild winters in the late 1960 s followed by very harsh conditions from 1972 to the present. Smith and Dobson (1984) estimate the standard deviation of annual-mean air-sea heat flux to be $19 \mathrm{~W} \mathrm{~m}^{-2}$ as compared to the mean value $-28 \mathrm{~W} \mathrm{~m}^{-2}$ between 1946 and 1974 (individual years ranging from -7 to $-87 \mathrm{~W} \mathrm{~m}^{-2}$ ). The upward heat flux provides considerable energy to the atmosphere (Fig. 3), for its intensity is comparable with the heat flux maximum seaward of the Gulf Stream (which we refer to as the "Bunker Bullet" after Bunker 1976).

The Labrador Sea is vulnerable to variation even under a constant atmospheric climate. Input of buoyant freshwater from Canadian runoff, local sea ice cycling, local precipitation, and low salinity water from the Arctic (via the Canadian Archipelago and Fram Strait) competes with the circulation of highly saline, warm (typ- 


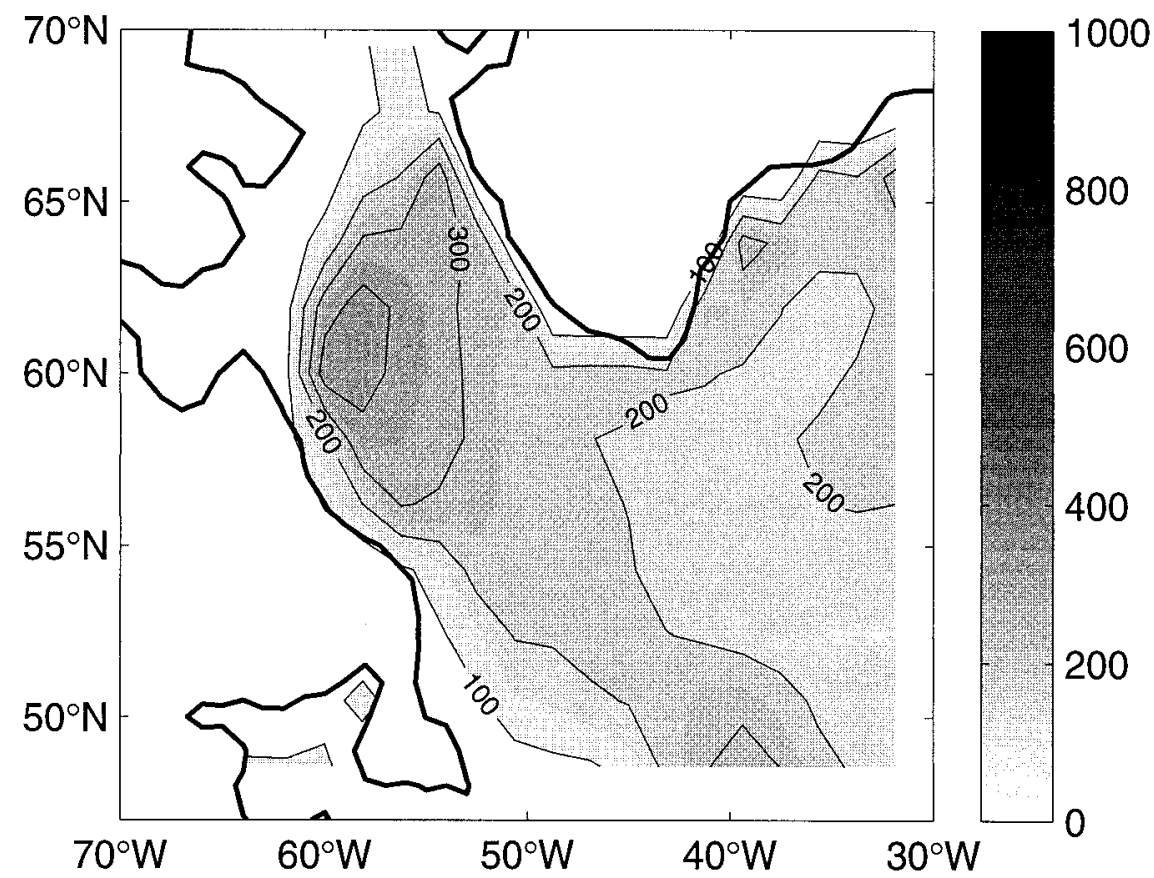

FIG. 3. Average heat loss in the Labrador Sea, Nov 1994-Mar 1995 from ECMWF. This region typically has the largest heat loss in the North Atlantic, exceeding $-400 \mathrm{~W} \mathrm{~m}^{-2}$. The data are subject to numerous assumptions about the ice cover and atmospheric boundary layer physics, as they are reconstructed from assimilating land-based radiosonde data into a circulation model.

ically $4^{\circ} \mathrm{C}, 34.95 \mathrm{psu}$ ) water of subtropical origin, which we refer to as Irminger Water. Cooling-driven convection must overcome the buoyancy barrier in the upper ocean. While the relative strengths of these many freshwater sources are not yet known, they combine with denser Irminger Water to make the convective product LSW, which currently lies near $2.7^{\circ} \mathrm{C}, 34.83$ psu.

Deep convection here is distinguished in several ways from the important observations in the Mediterranean (e.g., Schott et al. 1996) and Greenland Sea (Schott et al. 1993): first, in the close proximity to the waveguide of the deep western boundary of the Atlantic, which causes new LSW to penetrate rapidly equatorward as part of the upper North Atlantic Deep Water (Lee et al. 1990); second, circulation of LSW about the subpolar gyre can be rapid (Sy et al. 1997) and entrainment interaction with the dense Denmark Strait Overflow is intense (McCartney 1992); third, the size $(\sim 600 \mathrm{~km}$ diameter) of the LSW lens of weakly stratified water is greater than either the convective region in the Greenland Sea $(\sim 100 \mathrm{~km})$ or the Mediterranean $(\sim 50 \mathrm{~km})$; fourth, the convective history of the LSW is closely tied to the dominant atmospheric variability of the region, the NAO (Dickson et al. 1996); and fifth, the temperature-salinity regime is distinct: the central Labrador Sea is ice free and warm relative to the Greenland Sea, colder and more sensitive to freshwater surface buoyancy than the Mediterranean. The proximity of the Labrador Sea to northern Canada and the Arctic make it responsive to the hydrologic cycle of the Northern
Hemisphere and the cycle's possible intensification by global warming.

The average potential temperature and salinity between 1000 and $1500 \mathrm{~m}$, taken to represent LSW, have wandered on a roughly counterclockwise loop in $\theta-S$ space, over the range $2.7^{\circ}-3.6^{\circ} \mathrm{C}$ and $34.83-34.9$ psu (34.65-34.69 $\mathrm{g} \mathrm{kg}^{-1} \sigma_{1.5}$ ) from the earliest stations of the Danish ship Tjalfe (1908-09) and the British ship Scotia (1913) to the present (Rhines and Lazier 1995). We find ourselves close to the densest, coldest, freshest LSW on record. This kind of trajectory occurs also in numerical models of the thermohaline behavior of the circulation (e.g., Delworth et al. 1993). We stress (Dickson et al. 1996) that direct response to changing atmospheric forcing is the most obvious "first cause" of LSW variability, and the variability inherited from it by the middepth World Ocean. Yet the long advective memory of the salinity and temperature fields does argue for "ocean-only" oscillators, or at least for a changing sensitivity of the ocean's response to convective forcing. These oscillators usually involve the dependence of net convective water-mass transformation on the intensity of meridional circulation, given a relatively unchanging air-sea buoyancy flux. The famous "Great Salinity Anomaly" that passed through the Labrador Sea about 1969-71 certainly inhibited deep convection, but it was its coincidence with a blocking high over Greenland that brought exceptionally mild winters to the Labrador Sea; weak atmospheric forcing, rather than advected 

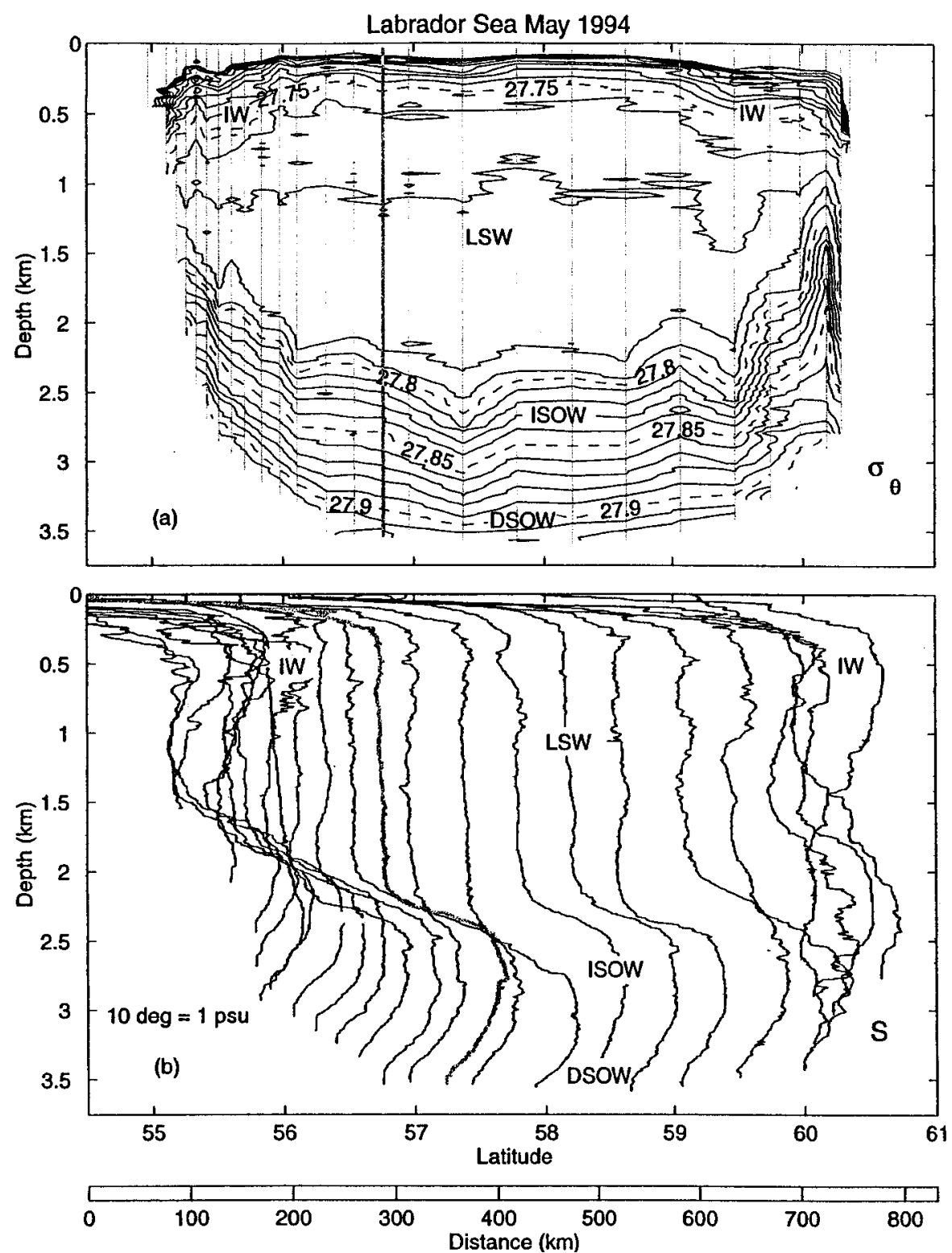

FIG. 4. May 1994 SW-NE section across the Labrador Sea on a line intersecting the mooring (see Fig. 2). Both contours of potential density (a) and offset salinity profiles (b) are shown. Potential density contours are from $\sigma_{0}=27.65$ to $\sigma_{0}=27.95 \mathrm{~g} \mathrm{~kg}^{-1}$ with a contour interval of $0.01 \mathrm{~g} \mathrm{~kg}^{-1}$. The salinity profiles in (b) have been offset so that the latitude of each profile is given by its value at $1.5 \mathrm{~km}$. Gray lines in (a) mark station locations, with the thick gray line marking the station nearest the mooring; the salinity profile from the mooring station is also denoted in (b) by a thick gray line. The high salinity of the Irminger Water (IW) boundary current is visible at both ends of the section, between 250 and $1000 \mathrm{~m}$, as are the stably stratified Iceland-Scotland Overflow Water (ISOW) and upper Denmark Strait Overflow Water (DSOW) underneath. The core of nearly homogeneous Labrador Sea Water (LSW) is, by late spring, capped with a low-salinity restratification, and its upper kilometer contains vertical finestructure. The base of the LSW and the ocean floor are both nearly isopycnal.

freshwater, was primarily responsible for the weakening and shutdown of deep convection during 1969-71.

The May-June hydrographic sections between Hamilton Bank, Labrador, and Cape Desolation, Greenland, carried out annually by Bedford Institute of Oceanography since 1990, provide important support for this mooring experiment. The section for May 1994 (Fig. $4 a)$, taken at the time the mooring was deployed, shows the thick lens of LSW following a moderately cold winter. A density of $\sigma_{0}=27.77$ (or $\sigma_{1.5} \sim 34.68$ ) is currently the approximate divider betweeen deep and shallow LSW, corresponding to downward and upward isopyc- 

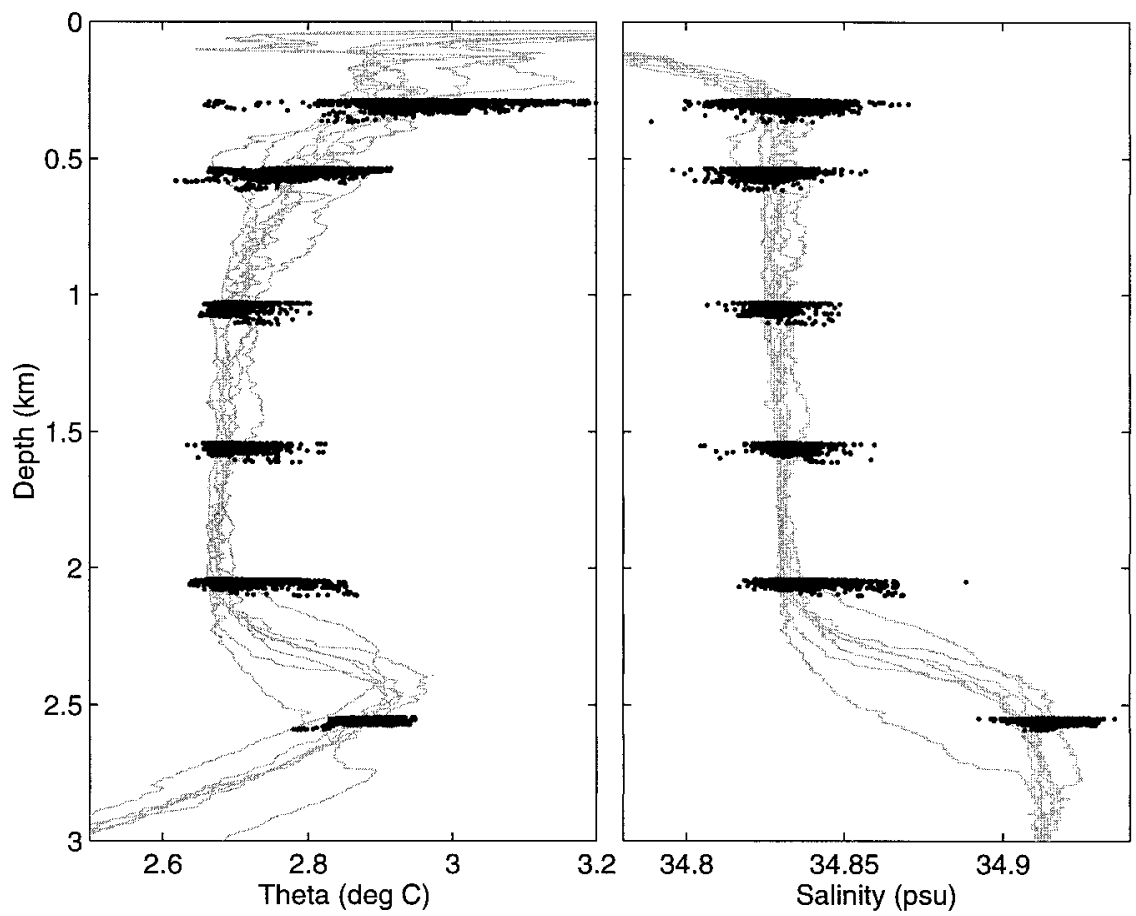

FIG. 5. Mooring $\theta$ (a) and $S$ (b) for the first two weeks of its deployment, along with CTD casts taken within the Labrador Sea gyre at around the same time. The CTD casts converge to a tight range of values between $\sim 500$ and $\sim 2000 \mathrm{~m}$. The much broader scatter of the mooring data is in part due to rare advective events (see appendix).

nal deflection. By late spring the upper $300 \mathrm{~m}$ shows water of lower salinity than the LSW beneath. The profiles are riddled with finestructure (Fig. 4b), possibly the collapsed product of horizontal variations in properties at the end of winter. When the profiles are superimposed, the salinity between 1000 and $2000 \mathrm{~m}$ is seen to be remarkably uniform across the section (Fig. 5). The winters of 1990-93 were particularly cold and windy and they left behind a legacy of well-stirred LSW at depth. The less severe winter of 1993/94 shows much more stratification in the upper $1000 \mathrm{~m}$, and yet still has a uniform deep water. The northeast Atlantic Deep Water (NEADW), part of which originates as Iceland-Scotland overflow water (ISOW) at $\sim 2500 \mathrm{~m}$ depth, provides a "basement" to the convection: its strong stratification, with an actual temperature inversion, is very difficult to penetrate. The isopycnal surfaces (Fig. 4a) illustrate this basement and also show that LSW lies at densities $\sigma_{1.5} \sim 34.68\left(\sigma_{0}=27.77\right)$ just greater than the warm, saline Irminger Water $\left(\sigma_{0}=27.6-27.7\right)$, which is visible in Fig. 4 as a salinity maximum and a thickening of isopycals between 200 and $1000 \mathrm{~m}$ at both edges of the section. Yet LSW density is much greater than that of the significant low-salinity boundary currents $\left(\sigma_{0}=27.4-27.6\right)$, particularly the Labrador and West Greenland Currents on the respective continental shelves.

Hydrographic expeditions to the region have been carried out intermittently during this century, though only a few of these have occurred during winter (notably Erika Dan in 1962; Hudson in 1966, 1976 and 1978, and recently the Hudson and Knorr in 1997 and 1998). The only three-dimensional surveys before 1996 were the March-May 1966 (and August 1965) Hudson sections (Grant 1968) and the Erika Dan sections reported by Worthington and Wright (1970). Convection was understood at the time more on the basis of circumstantial evidence than direct observation. The Clarke-Gascaard work of 1976 was the first systematic experiment, and succeeded in observing convection to about 2000-m depth with attendant velocity measurements.

Observations along the coasts of Greenland and Labrador, often made in connection with fisheries interests, have helped to establish the climatological variations (e.g., when cod were found spawning off Greenland in the unusual, suddenly arriving warm water of the early 1930s). But it was the establishment of the network of weatherships after World War II in support of transAtlantic air travel that provided the first extensive database for winter convection. OWS Bravo $\left(56.5^{\circ} \mathrm{N}\right.$, $51.85^{\circ} \mathrm{W}$ ), manned by the U.S. Coast Guard, carried out surface meteorogical measurements from 1946 to 1974 and deep hydrographic stations from 1964 to 1974.

Long time series in the deep ocean are extremely rare, and extremely valuable. A prior example at high latitude is the deep mooring array in the Denmark Strait over- 


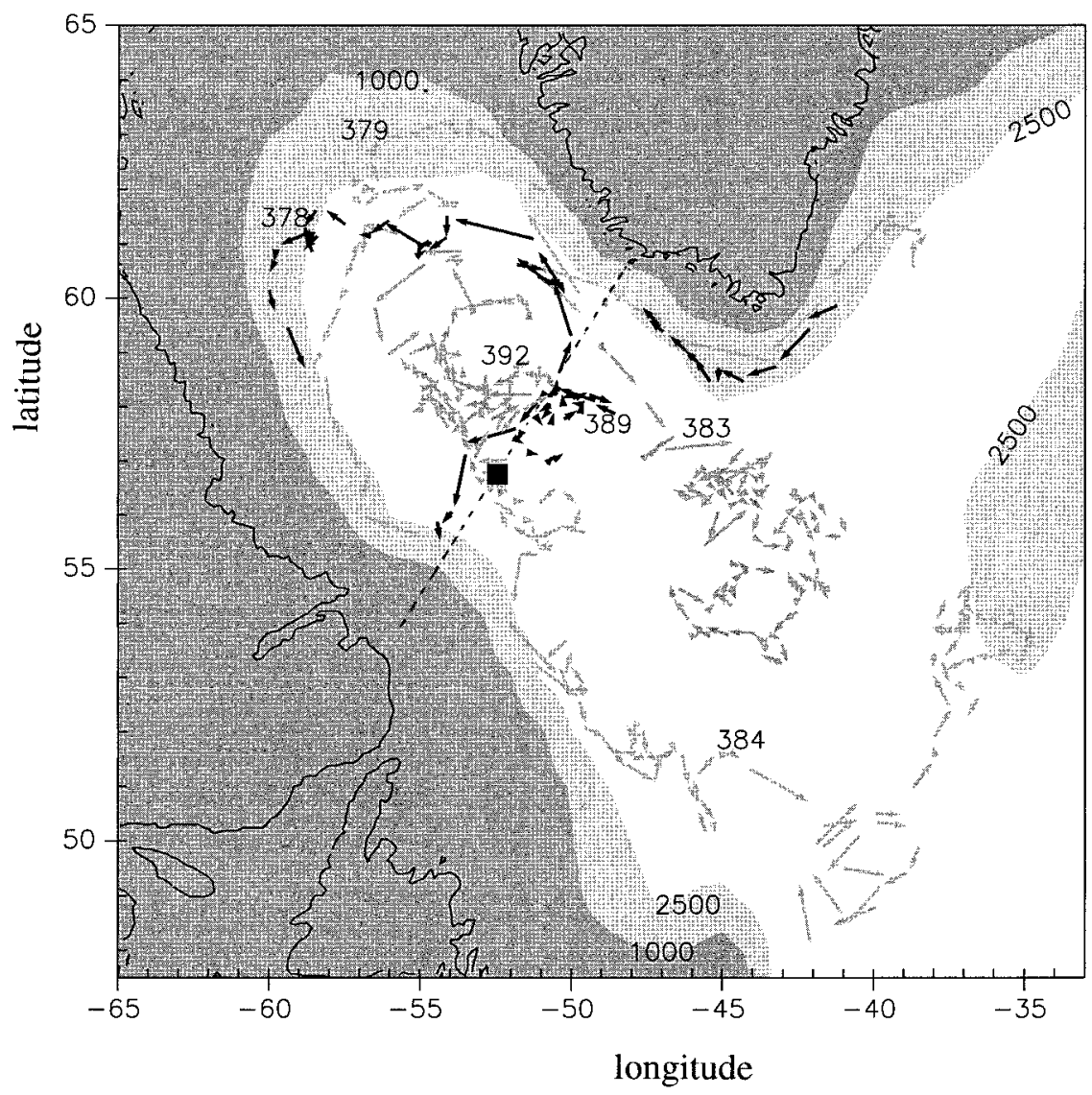

FIG. 6. Bravo mooring location (black square) and PALACE float trajectories for launches in Nov 1994 and May 1995, followed through Jun 1996. The hydrographic line (Fig. 4) is shown with dashes. Several floats $(378,383,384)$ launched in the Labrador Sea interior escape into the boundary current or beyond, while others $(389,392)$ remain on the interior of the gyre for many months. The tracks of floats 384 and 392 both originated within $30 \mathrm{~km}$ of the Bravo mooring.

flow water (DSOW: Dickson and Brown 1994). The OWS network provided the dominant dataset of this kind; its one surviving member, OWS Mike in the Norwegian Sea, has been maintained with uniform technology from 1949 to the present. Important high-latitude mooring experiments have begun to explore the annual cycle and air-sea interaction [e.g., the Greenland Sea Experiment (Schott et al. 1993) and the Marine LightMixed Layer Experiment (Pluedemann et al. 1995)]. In the Labrador Sea, Rhines (1994) describes the use of moorings to portray the deep-convective annual cycle.

Present measurement technology allows site moorings to gather some of this information at reasonable cost, and newer technologies (profiling CTD moorings, autonomous undersea vehicles, and drifting, profiling floats) may soon be economical alternatives. In this paper we describe the first year's observations from a 15instrument mooring funded by NOAA, intended to be the beginning of a site study of Labrador Sea Water, and make comparisons with the first set of data from an array of drifting PALACE floats released in the region.

\section{Plan of the experiment}

Spurred by the image of convection seen in the temperature records from the 1987/88 mooring array Rhines and Lazier 1995; Rhines 1997) we chose a site about $150 \mathrm{~km}$ seaward of the boundary current system, which lies on the Labrador continental slope. A convection mooring equipped with 15 instruments was deployed by the CSS Hudson at $56^{\circ} 45.2^{\prime} \mathrm{N}, 52^{\circ} 27.5^{\prime} \mathrm{W}$ in May 1994 (Fig. 6). It was a joint effort of the University of Washington (funded by NOAA and ONR), Canada's Bedford Institute of Oceanography, Institut für Meereskunde (Germany), and Institute of Ocean Sciences (Canada). The project was additionally stimulated by a plan of the U.S. Office of Naval Research to carry out an intensive Deep Convection Experiment in 1996-98, and by much subsequent ONR support.

Six Aanderaa RCM-8 current meter-temperature recorders, seven Sea-Bird Seacat conductivity-temperature recorders, a Weather Observation Trough Ambient Noise (WOTAN) recorder, and an RD acoustic Doppler current profiler were mounted on a subsurface mooring 
with an uppermost float $98 \mathrm{~m}$ beneath the surface in water of depth $3480 \mathrm{~m}$ (Fig. 7). The upward-looking acoustic Doppler current profiler (ADCP) measured profiles of horizontal and vertical velocity between $260 \mathrm{~m}$ and $480 \mathrm{~m}$ depth, and also recorded sea-surface reflections; the ambient noise and surface Doppler signals give estimates of wind speed and direction, respectively (Lemon et al. 1984; Schott 1989). The 13 temperature records spanned depths from $100 \mathrm{~m}$ to $3426 \mathrm{~m}$. Unfortunately the necessity to use subsurface moorings in this harsh environment, together with the failure of the uppermost Seacat at $100 \mathrm{~m}$, prevented us from recording the heat content of the upper $120 \mathrm{~m}$, where about onehalf of the annual $4 \times 10^{9} \mathrm{~J} \mathrm{~m}^{-2}$ of heat storage occurs. Six profiling neutrally buoyant PALACE floats were launched on a November 1994 cruise of the vessel $M e$ teor [four of these along the line of the annual hydrographic section (Fig. 6), and two in the Irminger Sea] and two more were launched the following May. The floats drifted at 1300 to $1500 \mathrm{~m}$ depth, and profiled $T$ and $S$ to the surface on an approximately 8 -day cycle. In doing so they caught the upper-ocean heat content missed by the mooring.

All the mooring instruments returned good data with the exception of the uppermost Seacat $T / S$ recorder, which had been modified to measure dissolved oxygen and total gas tension. This instrument was destroyed during an unexpectedly large vertical excursion of the mooring $(\sim 750 \mathrm{~m})$ in early April. The same excursion initiated a leak in the ADCP that terminated its recording later in April, and also caused the uppermost Aanderaa to fail around the same time.

Instrument calibration to the levels of interest here $(\sim 0.01$ for $\theta, \sim 0.005$ for $S$ ) is challenging, and we found that the intense small-scale $\theta / S$ finestructure in the Labrador Sea hinders comparisons between CTD stations and moored instruments. An additional complexity for the salinity calibration is due to the importance of the pressure contribution to the equation of state: $20 \mathrm{db}$ vertical movement of an instrument will cause a $0.01 \mathrm{psu}$ change in the apparent salinity for a given conductivity and temperature, in the sense of decreasing salinity with increasing pressure. Unexpectedly strong, barotropic currents caused the mooring to tow by more than $100 \mathrm{~m}$ on numerous occasions (at the extreme by $750 \mathrm{~m}$ ), so it is of great importance to know accurately the depth of each instrument. We had pressure gauges on two of the instruments, and used a numerical model of mooring response to currents together with these observations to infer the depths of all instruments. On subsequent deployments of the mooring we have installed more pressure instruments. A detailed discussion of the calibration for both $\theta$ and $S$ is given in the appendix; we judge the relative rms accuracy (over periods of days to a month) to be better than $0.005 \mathrm{psu}$, while absolute accuracy over the entire year is better than $0.01 \mathrm{psu}$. Measurement improvements are currently being made, for example lowering all the Seacats to-

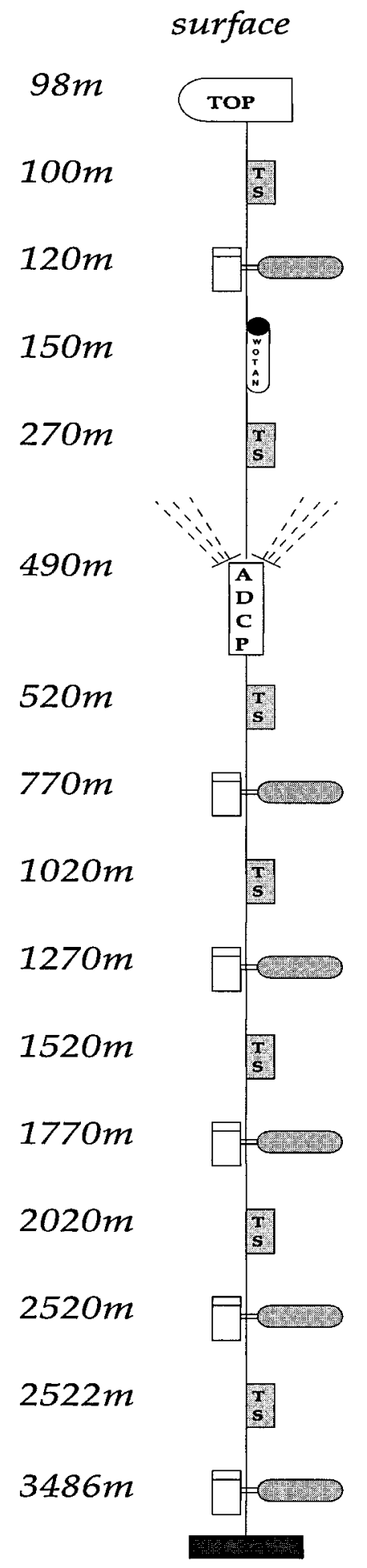

FIG. 7. Schematic diagram of the mooring, showing the nominal locations of the Seacat $T / S$ recorders, the Aanderra Current Meters, the upward looking ADCP, and the ambient sound recorder (WOTAN). All but one of the instruments, the uppermost Seacat, returned good data. 

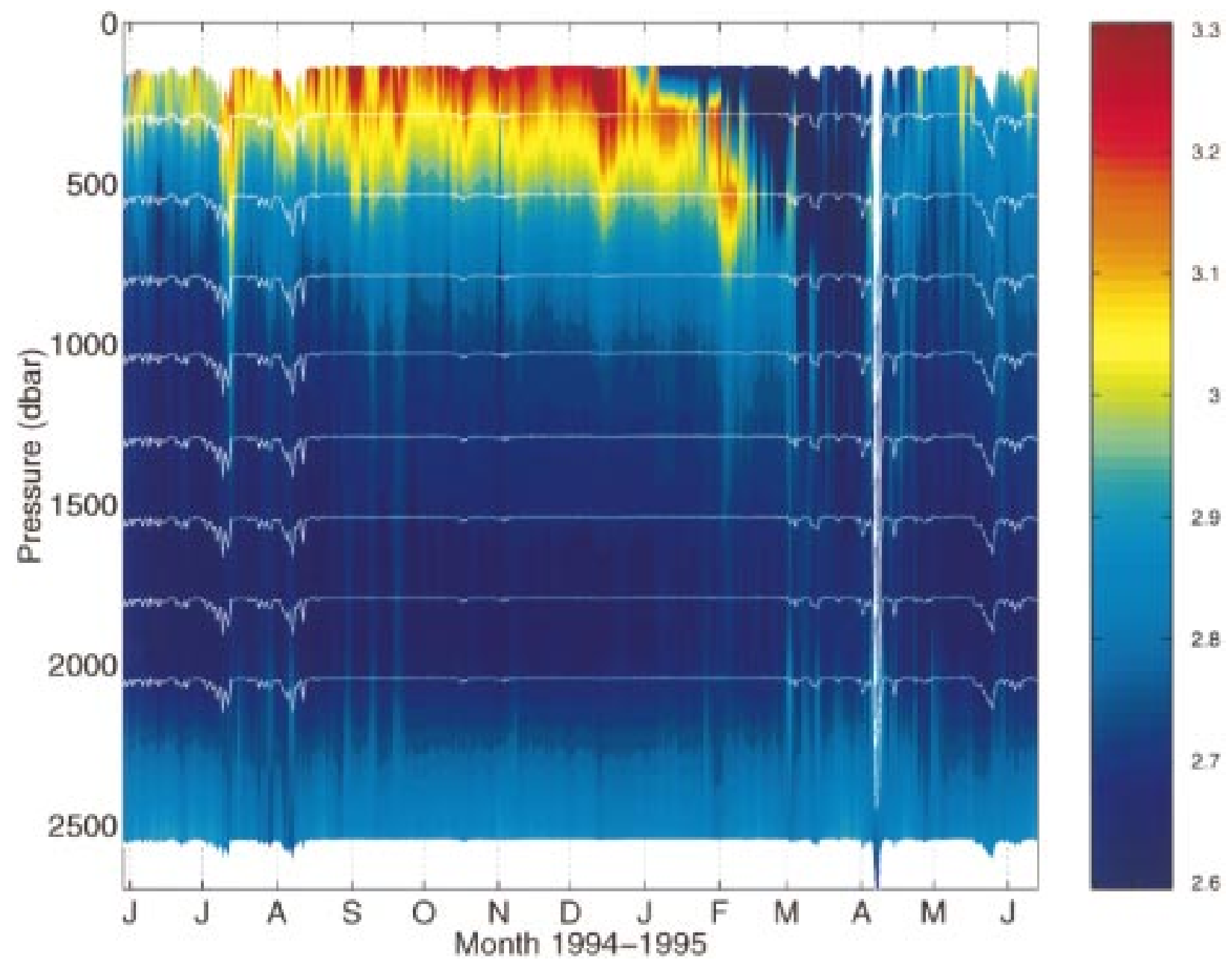

FIG. 8. The yearlong temperature record, contoured over ten instruments between 110 and $2510 \mathrm{~m}$. White lines show the pressures at the instrument depths, which were determined by combining measured pressure at the $110-\mathrm{m}$ and $1010-\mathrm{m}$ instruments with a mooring model (see appendix). Warming continues until late winter, when the deepening convective mixed layer brings cooled water down from the surface. By March cooling is evident as deep as $\sim 1500 \mathrm{~m}$. In this and other time series plots letters mark the first day of each month.

gether with a CTD, giving an intercalibration profile just before deployment.

\section{Temperature and salinity fields}

The time series of potential temperature over the year (Figs. 8 and 9a) shows gradual warming, which is interrupted in the wintertime by sudden cooling due to deep convection. The corresponding evolution on the $\theta-S$ plane is summarized in Figs. 10a-f (typical CTD casts taken from the Labrador Sea interior and the boundary current are also shown). The upper water column progresses slowly toward warmer, saltier, less dense properties during the summer and fall over the upper $\sim 2 \mathrm{~km}$, then suddenly becomes colder and fresher with the arrival of deep convection in the winter. The range of $\theta / S$ variation is largest at the upper two instruments, 510 and $260 \mathrm{~m}$, which are located on isopycnals $\left(\sigma_{0} \sim 27.76\right.$ and $\sim 27.74$, respectively $)$ that curve down into the warm, salty core of the Irminger boundary current (see Fig. 4). The deepest Seacat (at $2512 \mathrm{~m}$, near the warm, salty extremum of the NEADW) is unique in that it has energetic fluctuations of $\theta, S$, and $\sigma_{0}$ occurring throughout the year, the result of isopycnal displacement during eddy events (section $4 b$ ).

In this section we look in greater detail at various aspects of this cycle of convection and restratification in roughly chronological order following the 1994-95 mooring record. Restratification during spring, summer, and autumn involves a roughly linear increase in temperature at fixed depths to a depth of $\sim 1500 \mathrm{~m}$, as the deep convective cooling is offset by the influx of warm, salty boundary current water (section $3 a$ ); a large-scale shift in the stratification also seems to be involved. During deep convection itself, density appears to be homogenized to $\sim 1000 \mathrm{~m}$ with more intermittent convective water-mass modification extending to $\sim 2000 \mathrm{~m}$ (section 3b). Both mooring data and CTD sections show 


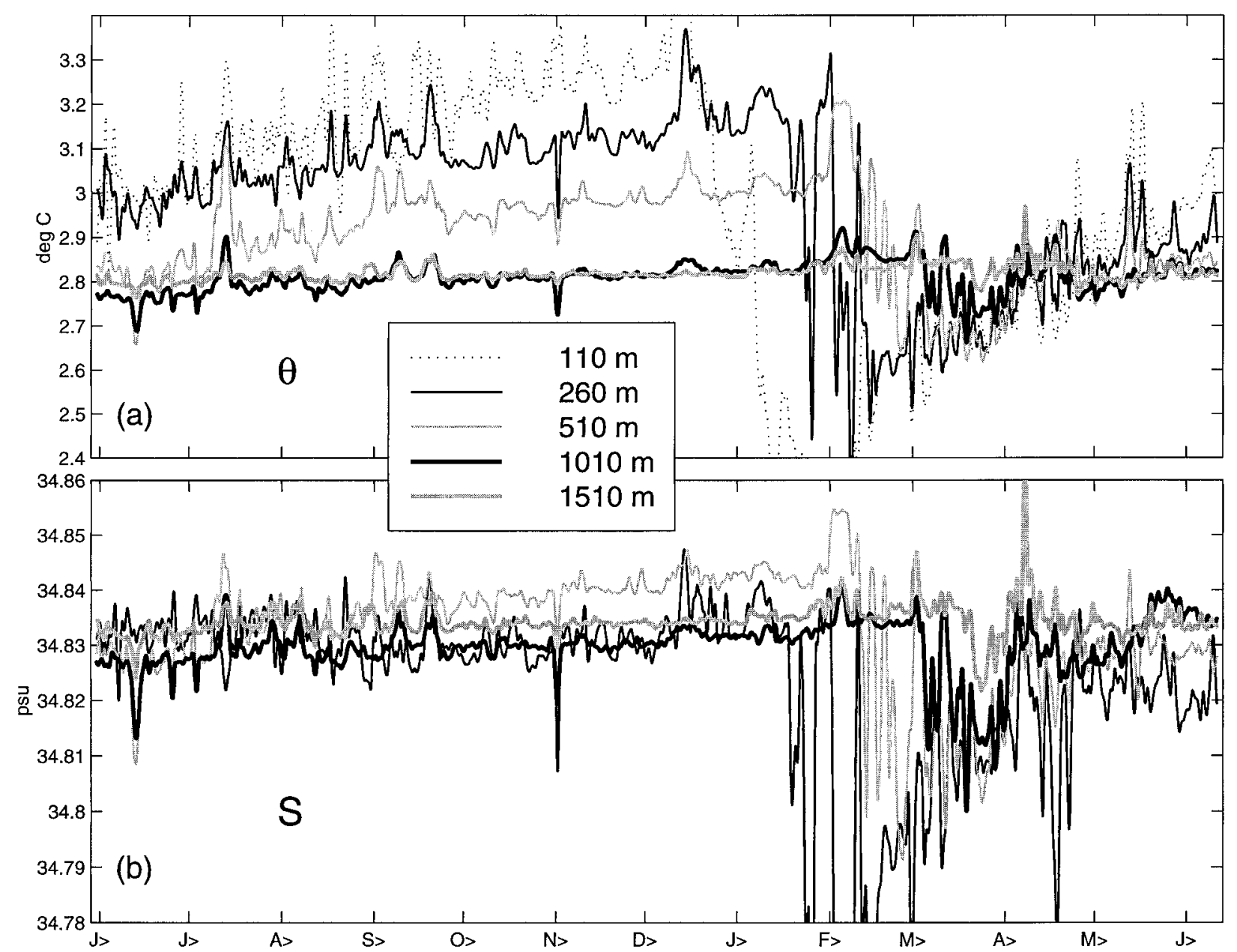

FIG. 9. Yearlong time series of water properties at Seacats $1510 \mathrm{~m}$ deep and shallower: (a) potential temperature, (b) salinity, and (c) potential density. Panel (a) includes the potential temperature at the 110-m Aanderra (dashed). All records have been lowpassed with a 48$\mathrm{h}$ Hanning filter to remove periods of $\lesssim 1$ day. The annual cycle is one of a slow progression towards increased temperature, salinity, and buoyancy, followed by a rush in the opposite direction during late winter.

the Labrador Sea to be rich with partly compensating $\theta$ and $S$ structure (section $3 \mathrm{~d}$ ), which develops rapidly following the end of convection and is thought to be partly the consequence of the depth and/or properties of the convective mixed layer varying with location. We find (section 3c) the range of $\theta / S$ scatter during deep convection is well bounded by a CTD profile of the preexisting stratification (limiting the warm, salty extreme of properties), and a "trajectory" of mixed layer properties found from a simple one-dimensional mixing model applied to that profile (forming the cold, fresh extreme).

\section{a. The restratification period}

The potential density time series (Fig. 9c) show systematic increase in buoyancy at fixed depths for instruments shallower than $\sim 1500 \mathrm{~m}$ throughout the nonconvectiving part of the year. A similar trend is observed in CTD section data from May and August 1996 Hudson cruises (Fig. 11) and ocean weather station (OWS) Bravo data from 1964-74 (not shown): from the mixed layer base to $\sim 500 \mathrm{~m}$, isopycnals appear to drop between spring and fall by $50-100 \mathrm{~m}$ across the interior of the Labrador Sea gyre. This seems to be a robust feature of the restratification process, and has consequences for the interpretation of the $\theta / S$ changes.

During most of the year temperature at fixed depths increases nearly linearly with time above $\sim 1500 \mathrm{~m}$. Note that this increase continues into the winter (Fig. 9a) until the arrival of the cold convected mixed layer, which reaches $260 \mathrm{~m}$ in early February. The salinity trend differs from the temperature trend in that it vanishes at about $260 \mathrm{~m}$ (more apparent in the $\theta-S$ plane, Fig. 10, comparing panels a and b) so that above this depth salinity may actually decrease with time at fixed depths. However, on isopycnal surfaces the entire water column above $\sim 1500 \mathrm{~m}$ is becoming warmer and more 

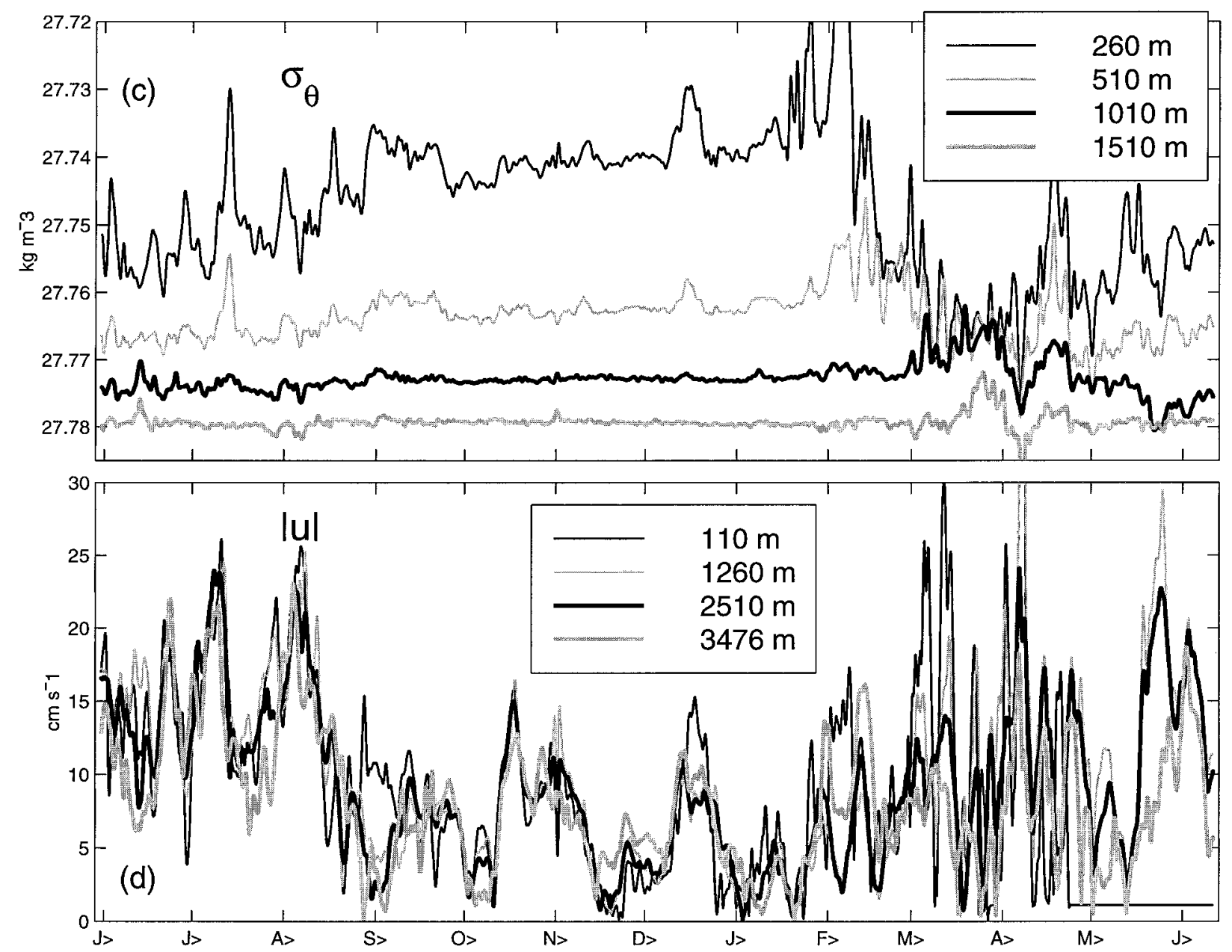

FIG. 9. (Continued) Also shown (d) is the current speed at the locations of four of the Aanderras (note the failure of the uppermost instrument in late April). Note the lower levels of high-frequency density variability and current speed during the middle third of the record (Sep-Jan).

saline, in other words more isopycnally similiar to Irminger Water. The vanishing of the salinity trend at 260 $\mathrm{m}$ is connected to the sinking of isopycnals and the strongly negative vertical salinity gradient above that depth (note initial CTD cast in Fig. 10: the resulting vertical advection of freshwater roughly balances at $\sim 260 \mathrm{~m}$ the opposing salinization process).

The $\theta / S$ trends between June and February, then, reflect warming and salinization on isopycnal surfaces, which are descending with respect to the instruments. From the $\theta-S$ diagram it is clear that the water properties approach values of the Irminger Water in the boundary current. More subtle changes are also occuring: within the same isopycnal range in which the maximum sinking occurs (roughly $\sigma_{0}=27.6$ to $\sigma_{0}=27.7$ ) the buoyancy frequency $N$ is decreasing. This also indicates the influence of Irminger Water, which has thicker isopycnal layers (i.e., lower $N$, and also lower potential vorticity) than the interior Labrador Sea Water within this isopycnal range
(Fig. 4). Although it may seem counterintuitive that $N$ should decrease during restratification, this is true only on isopycnals, while at fixed depths $N$ increases throughout the water column [if one draws horizontal and vertical lines connecting the June and November profiles (Fig. 11) this distinction becomes clear].

This transition of the water column to more Irmingerlike properties could be explained either by large-scale advection or by modification of the Labrador Sea Water through mesoscale exchange of water parcels across the boundary current. Although the differentiation between these two mechanisms is difficult to make on the basis of an Eulerian mooring measurement alone, evidence from a number of sources seems to rule out the advection hypothesis. Large-scale advection requires a mean flow operating on a mean gradient, and both appear to be missing here. PALACE float tracks show only weak systematic circulation seaward of the strong cyclonic boundary current (see floats 389 and 392 in Fig. 6), 

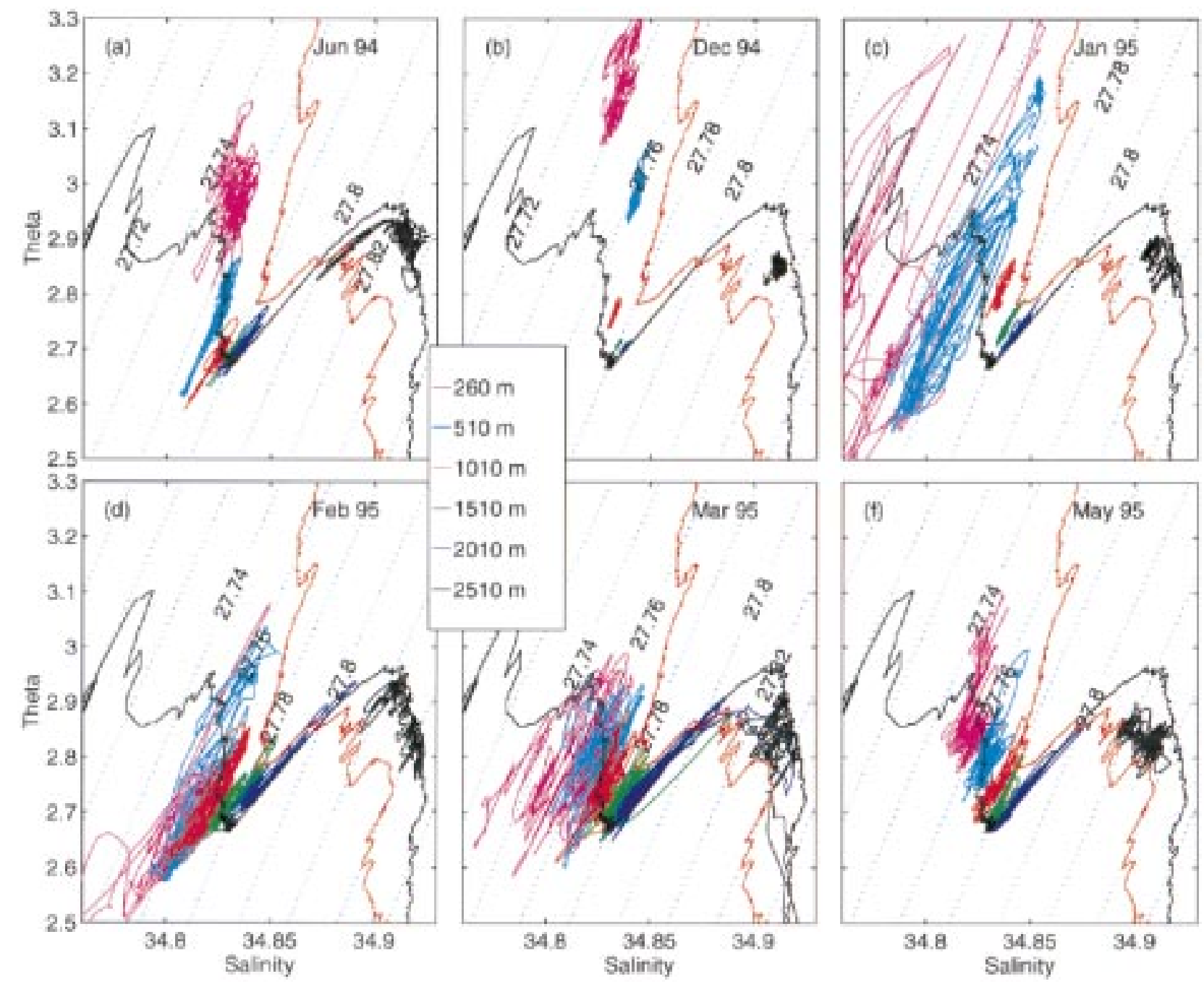

FIG. 10. $\theta-S$ plots for six months showing stages in the evolution of the water column at the six Seacats. CTD casts taken near the time of deployment are shown for the mooring location (black) and for a point near Greenland (red) within the warm, salty boundary current. Dotted lines are $\sigma_{0}$ contours. Note that $\theta-S$ points for three of the instruments $(2010,1510$, and $1010 \mathrm{~m})$ are nearly indistinguishable from each other; these are all within the range of nearly homogeneous Labrador Sea Water. Between Jun and Dec the water column above $\sim 1500$ $\mathrm{m}$ progresses toward lighter, warmer, saltier properties. Beginning in Jan deep convection results in increased scatter and denser, colder, fresher water; but by May the water column has returned to an intermediate state.

consistent with maps of dynamic height (Lazier 1973) suggesting the isolation of the Labrador Sea Water within closed streamlines. A pair of sections in May and November 1996 show that the restratification is a period of remarkable homogenization along isopycnals, indicating an efficient mixing mechanism. Thus the $\sim 600$ $\mathrm{km}$ Labrador Sea Water lens is becoming more homogenous even as it becomes warmer and saltier, whereas lateral advection requires a lateral gradient to be present in the region of change.

While lateral advection seems improbable, exchange of water parcels with the boundary current clearly occurs. Numerous eddies of Irminger-type water are advected past the mooring ( $\$ 4 \mathrm{~b})$, and PALACE floats tracks show examples both of ejection from the interior into the boundary current (float 384) and of incursion from the boundary current into the interior (float 383). The homogenization of the Labrador Sea Water lens itself may be a result of this eddy activity.

The changes in water properties, isopycnal thickness ( or $N$ ) and isopycnal depths, seem to be components of a systematic adjustment of the gyre during restratification due to eddy fluxes from the boundary current. Consistency among the various tracers can be checked in 1996, since during this year both a May and November section are available, and all three $(S, \theta$, as well as $f / N$, which approximates the full potential vorticity) show a mixing ratio during restratification of roughly one part recently convected water to one part boundary current. The sinking of isopycnals may therefore be a 


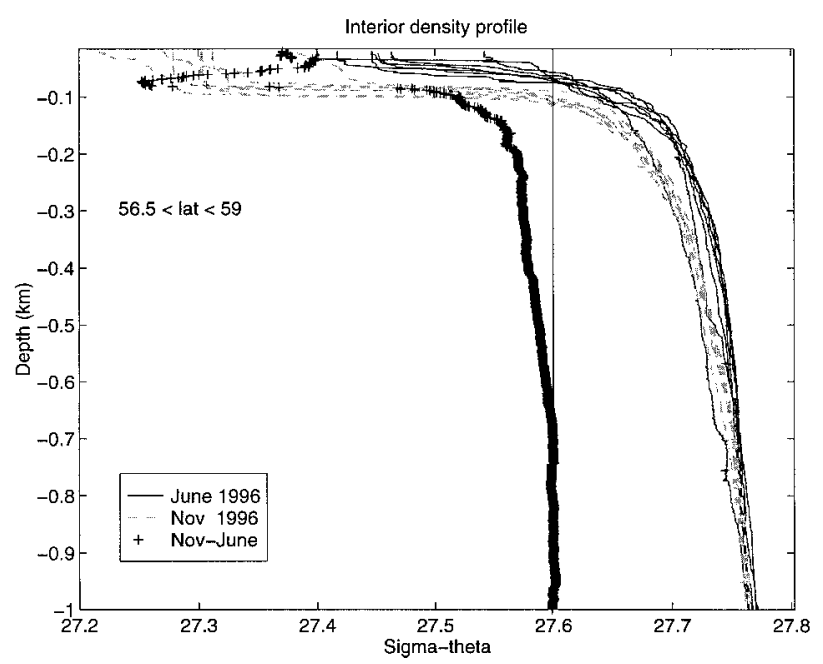

FIG. 11. CTD $\sigma_{0}$ profiles from the interior of the Labrador Sea $\left(56.5^{\circ} \mathrm{N}<\right.$ latitude $<59^{\circ} \mathrm{N}$ ) for May (solid) and Nov (dashed) 1996 All isopycnals between $\sim 100$ and $\sim 700 \mathrm{~m}$ appear to drop by $50-75$ $\mathrm{m}$. Also shown is the average difference between the two groups of profiles (crosses), the magnitude of which increases upward. The scale for the difference is the same as for the profiles, but has been offset by 27.6 so that the solid vertical line is the zero line.

consequence of the surface-intensified influx of lowpotential vorticity boundary current water. Such an eddy-driven "bolus flux" adjustment of the large-scale density structure would be akin to the meridional circulation of the atmosphere (Gill 1982), for example, in which standing and transient eddies flux heat and momentum poleward across the jet stream. Purely adiabatic sinking of isopycnals, on the other hand, would not result in the observed change in $N$.

The near-surface freshening is an important component of the restratification, which was well observed by PALACE floats during 1994-95. The Labrador Sea is capped by a layer of low-salinity water (Fig. 4) that provides for the characteristic freshness of the Labrador Sea Water through convective mixing, and thereby eventually impacts the $\theta / S$ properties of the deep World Ocean. Historical data from OWS Bravo can be used to quantify the magnitude of the annual cycle of the salinity anomaly integrated from the surface to $1000 \mathrm{~m}$. This had a mean amplitude range equivalent to $0.6 \mathrm{~m}$ of freshwater over the years 1964-74. The surface currents encircling the Labrador Sea provide a likely source for this freshwater (particularly the shelf-trapped Labrador current on the western side), though both the specific mechanism for its influx as well as the contribution from local precipitation are not yet known.

Figure 12 shows two and a half years' worth of the salinity cycle above $600 \mathrm{~m}$ from PALACE float 392, which was trapped in the Labrador Sea interior during this period. The downward mixing of surface low-salinity water as the mixed layer deepens during the fall and winter is clearly evident. In the spring and summer, the low-salinity water layer extends beneath the mixed layer (to a depth of 50-100 m), a feature which is often observable in CTD sections and is associated with a temperature minimum. Isopycnal entry of this freshwater layer from the boundary currents is not possible since the fresh surface currents are too buoyant; isopycnals from the cold, fresh interior layer reach instead into the warm, salty Irminger Water. The submixed layer freshening/cooling could represent either a one-dimensional evolution due to air-sea fluxes during early spring restratification or an invasion of the boundary current water. In either case the freshening is a very shallow process (less than $\sim 200 \mathrm{~m}$ ) of the upper ocean.

\section{b. The deep convection period: Vertical homogenization}

The convective "window" is opened to great depth for a very short time and is accompanied by much chaos. As the surface layer is cooled $0.6^{\circ} \mathrm{C}$ colder than the deep water, overcoming its low salinity, it convects downward; this $\theta / S$ contrast between mixed layer and deep LSW provides an excellent tracer for convection. We expect, and find, that $\theta$ and $S$ are partially compensating; that is, their contributions to density tend to cancel (section 3d). About 15 December the 110-m temperature surges upward, then decreases rapidly, again almost linearly, for 50 days, until day-30 of 1995. The convective layer then reaches $260 \mathrm{~m}$ by day 35, cooling until day $45 ; 510 \mathrm{~m}$ by day 40 , cooling until day 85 ; $1010 \mathrm{~m}$ by day 60 , cooling until day 85 ; and $1510 \mathrm{~m}$ by day 85 , where the cooling is slight. On the $\theta / S$ plane (Fig. 10c) the range of $\theta / S$ properties in the upper water column suddenly increases in January as cold freshwater from the surface layer is mixed downward.

By March (Fig. 10d) convection reaches its deepest extent and isopycnals above $\sigma_{0}=27.78$ are at their coldest and freshest of the year. During most of March the potential density is homogenized over the top 1000 $\mathrm{m}$ to within $0.001 \mathrm{~g} \mathrm{~kg}^{-1}$, although this number is subject to long-term calibration uncertainties less than $0.005 \mathrm{~g} \mathrm{~kg}^{-1}$. The first arrival of convection at the two upper Seacats $(260$ and $510 \mathrm{~m})$ involves about 1 week of decreased density before the strong density increase begins. At first glance this appears to be penetrative convection, that is, kinetic energy-driven mixing at the convective layer base leading to a step discontinuity in density and a period of reversed (i.e., downward) buoyancy flux. However, the temperature change is in the wrong sense to be due to penetrative convection. Penetrative convection causes warming before cooling at a fixed depth in a temperature-only stratification, but here the stable salinity gradient requires the mixed layer to be colder than the underlaying stratification in order to deepen, so penetrative convection would result in a density decrease together with a temperature decrease. The observed decrease in density above $\sim 500 \mathrm{~m}$ coincides with the arrival of warmer, more saline water characteristic of the boundary current, so this initial density 


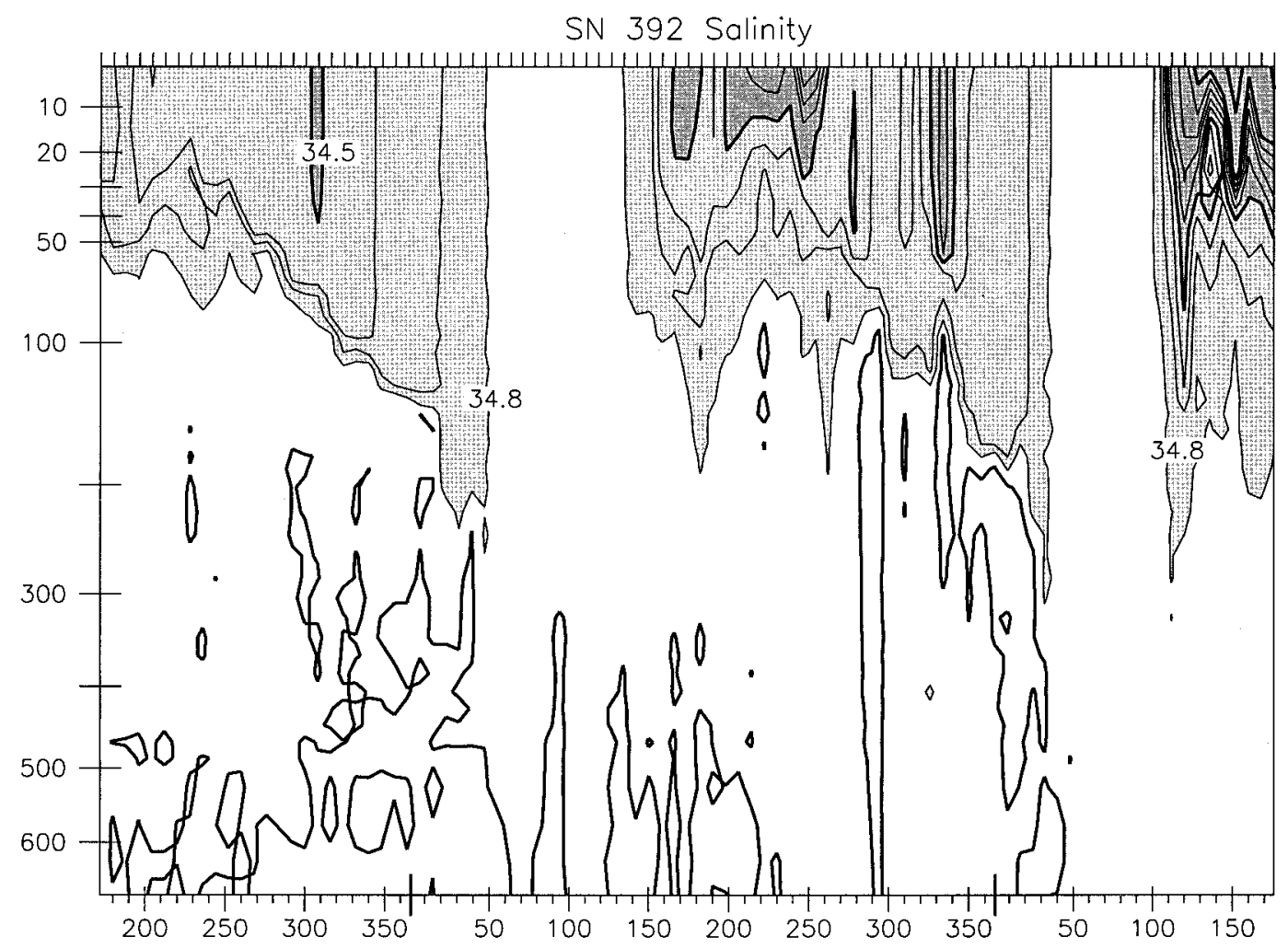

FIG. 12. Salinity from PALACE float 392 in the upper $600 \mathrm{~m}$ of the Labrador Sea interior for 1995-96. Note that the $y$-axis is stretched to accentuate the upper water column. Values less than 34.8 are lightly shaded, and those less than are 34.5 darkly shaded. The mixing down of surface freshwater as the mixed layer deepens in the fall and winter is clearly visible.

decrease must be the result of lateral advection rather than penetrative convection.

Another candidate for penetrative convection occurs deeper in the water column: between early and mid March the density observed at $1000 \mathrm{~m}$ drops by 0.006 , and temperature and salinity decrease as the water column is briefly homogenized in density to at least 1000 $\mathrm{m}$. Yet the density decrease at $1000 \mathrm{~m}$ coincides with a sudden doubling of the current speed in the upper water column (at 110 and $750 \mathrm{~m}$ ) to the highest values of the past six months. This suggests that here, too, we are seeing the advection of an eddy structure (within which convection has proceeded to a greater depth) past the mooring, with uplift of isopycnals rather than local penetrative convection explaining the density decrease. Thus we find, perhaps not surprisingly, no strong evidence for penetrative convection. Instead, the most striking feature of this dataset is lateral variability across a range of scales (discussed below, §3d). Energetic, nearly barotropic eddies sweep fluid past the mooring, so that the Eulerian records during convection are a quasi-random sampling of an $O(100 \mathrm{~km})$ diameter region of the sea.

The relatively long-term density homogenization above $\sim 1000 \mathrm{~m}$ is contrasted by evidence for much deeper but "patchier" convective penetration down to $\sim 2000 \mathrm{~m}$. For the $1000-\mathrm{m}$ and $1500-\mathrm{m}$ instruments, the increase in high-frequency $\theta$ and $S$ fluctuations is an indirect signature of convection reaching that depth since the weak stratification of the water column above $\sim 2000 \mathrm{~m}$ cannot account for such variability. However, isopycnal uplift (due to the advection of geostrophically balance cyclonic eddies) as well as mooring towdown may bring the 2010-m instrument to within the stably stratified NEADW beneath it, so at this depth high frequency variability alone is no longer a trustworthy indication of convection. More persuasively, time series of $\theta$ and $S$ at 1510 and $2010 \mathrm{~m}$ (not shown) show excursions during March and April to the coldest and freshest properties of the past eight months, for which deep convection is the only reasonable source. Some convective modification is therefore obvious far deeper than the observed $\sim 1 \mathrm{~km}$ depth of local density homogenization, another suggestion of the laterally variable convection. Perhaps the most direct evidence of the depth reached by convection is the comparison of January and March profiles of potential temperature from the mooring, in which month-long averages converge at about $1750 \mathrm{~m}$, which is thus the approximate limit of substantial convective modification (although horizontal advection could affect this conclusion).

The extent of vertical homogenization during deep 
convection is difficult to quantify on the basis of the 1994-95 data because the lack of pressure sensors on most instruments introduces an error into salinity (and therefore density) measurements (see appendix). We can address this question with data from the 1996-97 mooring, which had pressure sensors on all instruments. Potential density, potential temperature, and salinity all are homogenized to within instrumental accuracy during the times of most intense convection, except when stratified eddies pass by. Such vertical homogenization characterizes most of the fall/winter period as the mixed layer deepens. Potential temperature, the most reliably measured quantity, typically deviates by less than $0.05^{\circ} \mathrm{C}$ over the full depth of the mixed layer. The process of "grinding" down $\theta / S$ anomalies by three-dimensional turbulence must therefore be efficient, given the range of $\theta$ and $S$ in the initial water column; as the mixed layer deepens, the warmer, more saline water that is drawn into the mixed layer from below must be quickly assimilated. The unstable buoyancy profile required for convection is unmeasureably small (though it is occasionally seen in high-latitude vertical profiles in winter).

\section{c. Comparison with a one-dimensional model}

The relationship between the convectively modified water column and the original stratification can be explored by applying a one-dimensional mixing model of convection to CTD profile data. Convective mixed layer deepening is approximated by removing buoyancy from the uppermost data points of a CTD cast. The model surface mixed layer (which is constrained to be of vertically uniform properties) becomes denser until it is marginally unstable with respect to the underlying water. The model mixed layer is then deepened, encompassing the data point just beneath it, and the cycle of buoyancy loss and deepening is repeated. This model represents the limit of purely nonpenetrative one-dimensional convection.

The mixed layer properties $\theta_{\text {mix }}$ and $S_{\text {mix }}$ change both as a result of surface fluxes and due to the entrainment of the underlying stratification as the mixed layer deepens. For a given choice of surface fluxes (net heat flux and $E-P), \theta_{\text {mix }}$ and $S_{\text {mix }}$ are then functions of time, or alternatively of mixed layer depth, and can be plotted on a $\theta-S$ diagram. The resulting trajectory on the $\theta-S$ plane represents the progression in time of a hypothetical mixed layer's properties, and should be distinguished from a vertical profile.

Use of this model requires a CTD profile from the restratified water column. A November 1994 CTD survey of the Labrador Sea boundary currents extended far enough inward to capture the edge of the LSW at a single station (Fig. 13), roughly $50 \mathrm{~km}$ from the mooring. This cast appears similiar to the mooring measurements at the time, although it is somewhat warmer and more saline because it is closer to the boundary current. Mixing down this CTD profile with $E-P$ set to zero

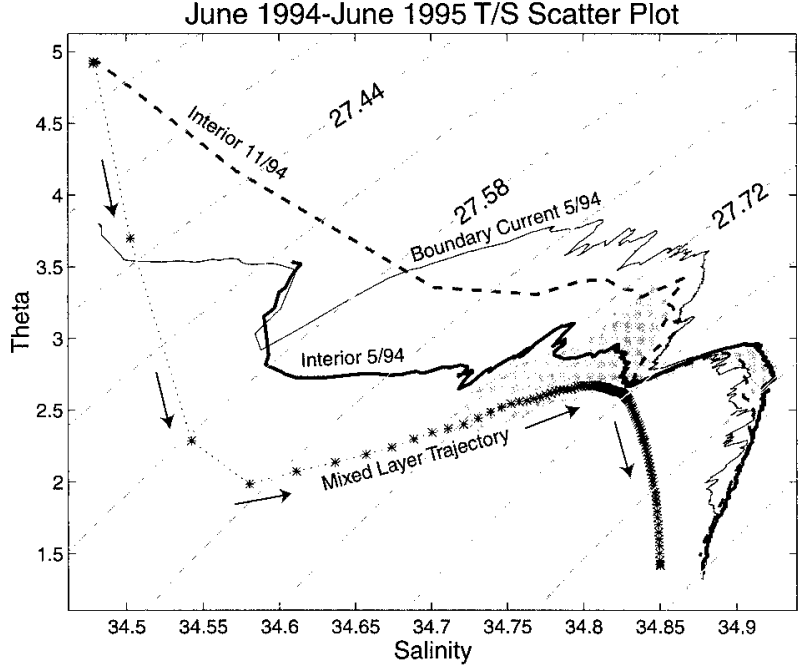

FIG. 13. $\theta-S$ scatter for the entire year together with several CTD casts and the output of a simple model of mixed layer property evolution (asterisks). The thick dark line intersecting the center of the $\theta-S$ scatter is a calibration cast taken in May 1994. The thin dark line is a CTD cast taken near the same time, but in the boundary current. The thick dashed line is a CTD cast taken $\sim 50 \mathrm{~km}$ from the mooring during November. Mixing down this CTD cast with specified surface fluxes, as explained in the text, yields a deepening mixed layer the properties of which evolve along the line marked with asterisks. The $\theta-S$ scatter for the year above $\sim 2500 \mathrm{~m}$ fills a wedgeshaped region between the warm, salty boundary current water and the cold, fresh water of the convective mixed layer trajectory.

yields the trajectory shown in Fig. 13. Although the surface flux values in the Labrador Sea during winter are poorly known, preliminary results from the winter 1996/97 experiment suggest evaporation and precipitation roughly balance (P. Guest 1997, personal communication); using realistically different $E-P$ values in the model does not significantly change the results.

Initially the trajectory evolution is controlled mostly by surface fluxes, and mixed layer properties move toward colder temperatures with minimal change in salinity. The mixed layer rapidly becomes colder and fresher than the underlying water. When the strong surface stratification is eroded, the entrainment of heat and salt from below as the mixed layer deepens become important. The mixed layer then becomes warmer and more saline until the top of the stably stratified NEADW is reached, which marks the lower limit of convective penetration in all but the most extreme winters.

Comparing the model to data shows the mixed layer trajectory approximates the cold, fresh limit of convectively modified water observed at the mooring (Fig. 13) and reproduces its evolution toward warmer, more saline properties as the winter progresses (see Figs. 10c,d). The triangular shape of $\theta / S$ scatter variations during deep convection thus appears to represent the mixing of purely convected water with the unmodified original stratification. The eventual water-mass product at the 


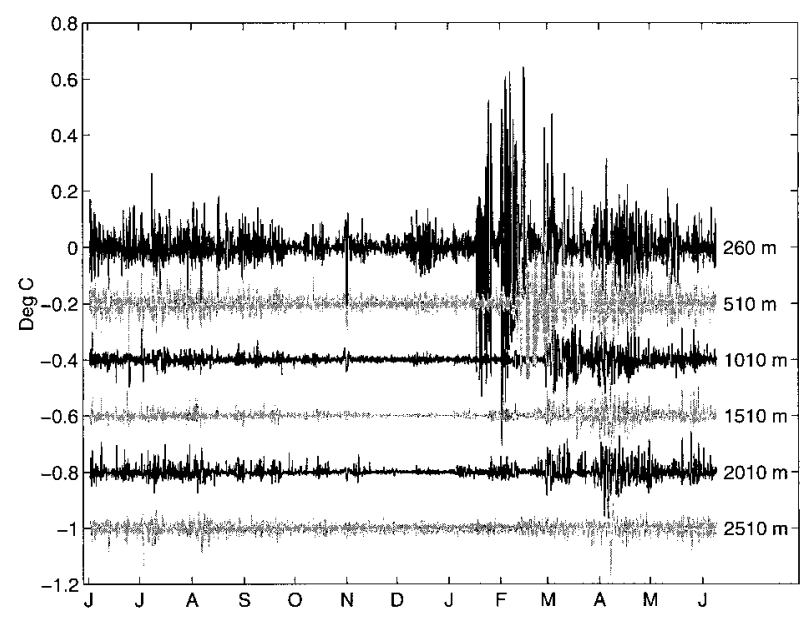

FIG. 14. High frequency $\theta$ flucuations at the six Seacats, determined by lowpassing the time series with 96-h Hanning filters and subtracting these from the originals. High-frequency variability is excited between Jan and Mar down to 2010 m, a signature of convectively generated lateral and vertical gradients.

end of convection season (Figs. 10e,f) lies isopycnally about midway between the mixed layer trajectory and the preexisting stratification.

\section{d. High-frequency variability and lateral $\theta / S$ structure}

The arrival of the convective mixed layer at a given depth is marked not only by colder, fresher water properties, but also by a sudden increase in the level of highfrequency energy in the temperature and salinity time series. High-pass filtered time series for the entire year (Fig. 14, based on a 96-h filter width) show the onset of high frequency variability coinciding with convective activity working its way downward through the water column. After convection ceases, the high-frequency variability weakens gradually for the entire year until the next convection season. Its decay is nearly exponential, with an $e$-folding time of about 170 days. This rate must reflect the efficiency of the cascade of tracers to very small scales, where final mixing and dissipation can occur. The association of high frequency variability with the convection season is not unique, however, since passage of long-lived mesoscale eddies at any time of year seems to elevate this variability (based on data from other years not shown here).

High-frequency variability is at least partly an indication of horizontal gradients ("lateral finestructure") being advected past the mooring. An increase in variability at a given depth may be due initially to the instrument passing in and out of the convective mixed layer, through internal wave heave or mooring motion, yet this would not be expected to persist as the mixed layer continues to deepen. Further, the temperature versus depth structure seen in an expanded version of Fig. 8 (not shown) for the deep convection

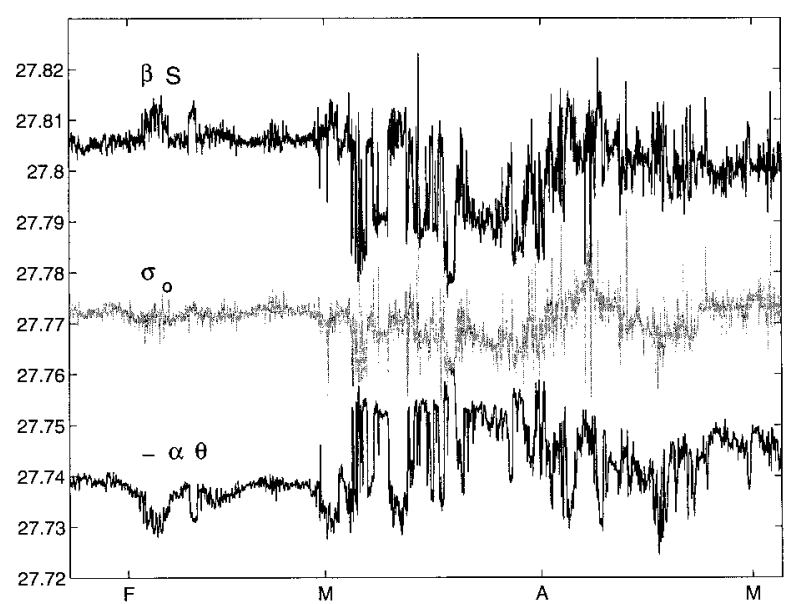

FIG. 15. Density $\left(\sigma_{0}\right)$ at $1010 \mathrm{~m}$ and its components, $-\alpha \theta$ and $\beta S$, for Feb 1995-Apr 1995. Convective penetration occurs near the beginning of Mar. Much of the high frequency $\theta$ and $S$ variance cancels out, leaving a $\sigma_{0}$ time series with significant low-frequency energy.

period shows the vertical scale of the $\theta / S$ anomalies can be very great, spanning several sensors (hundreds of meters) on the mooring. In such events vertical heaving cannot be the dominant effect; however, within the continuum of smaller vertical scales the relative importance of heaving and lateral advection is not yet known.

The amplitude of the high-frequency variability is typically $\sim 0.1^{\circ} \mathrm{C}$ in $\theta$ and $\sim 0.01 \mathrm{psu}$ in $S$ (between 250 and $1000 \mathrm{~m}$ ), but with sporadic events several times larger. This lateral inhomogeneity has a continuous spectrum, inferred to have typically (frequency) $)^{-2}$ spectral dependence for $\theta$ or $S$, which maps to a $k^{-2}$ wavenumber spectrum, from scales of a few hundred meters to tens of kilometers.

Density compensation (in which fluctuating temperature and salinity contributions to density tend to cancel) is significant: time series for February through April (Fig. 15) of the 1010-m potential density and its two contributors show compensation during both convective and at quiet periods. CTD profiles, which characterize the vertical finestructure, are in agreement with the mooring time series in that potential density profiles are much smoother than either $\theta$ or $S$ profiles (not shown). We can begin to quantify the level of dynamic activity seen in the time-dependent fields. In early February, for example, a cold, fresh perturbation passes the mooring with negligible density signal. At the arrival of convection the density fluctuations increase greatly (the standard deviation of density in March is six times its value in September), yet amount to typically $20 \%$ of the summed magnitudes of the $\theta$ and $S$ components of density.

These intense lateral variations in $\theta$ and $S$ are the combined result of lateral variation in both the preconvection water column (perhaps due to coherent eddies) and in the depth of convection. Lateral structure 
may lead to the vertical finestructure observed in CTD profiles (Fig. 4) as vertically homogeneous columns are tipped over, either by large-scale vertical shear or by small-scale intrusions. The isopycnal nature of the water column transition after deep convection ( $(3 e)$ as well as of the CTD finestructure itself both favor the latter mechanism. This lateral structure also seems responsible for the deep, intrusion-rich halocline observed in CTD casts observed in 1995 and other years $(\S 3 \mathrm{e})$.

Evidence for lateral structure of deep convection on a larger scale is found by comparing Lagrangian float data to the mooring results. The six neutrally buoyant PALACE floats provided vertical profiles of $\theta$ and $S$ at roughly 7-day intervals; profiles of $\theta$ from the three floats nearest the mooring are shown in sequence in Fig. 16. The line styles of the profiles match those of the float tracks (inset), on which bold dots mark the locations of the profiles shown. The profiles record the deepening of the convective layer, showing striking agreement with the moored instruments (plotted as a scatter of dots at fixed depths). The floats in addition show the state of the upper ocean, which is missed at the mooring. Great horizontal variability of the $\theta$ profiles is seen, especially in comparison with the relatively smooth vertical profiles. The comparison shows that much of the high-frequency structure seen in the time series (Fig. 14) must be due to lateral finestructure.

Basic questions remain as to the gyre-scale distribution of deep convection (distinguished from the small-scale patchiness, which the lateral finestructure appears to represent). On the one hand there is some evidence (e.g., Clarke and Gascard 1983) that the most intense convection occurs just offshore of the boundary currents, somewhat northwest of Bravo. There is, however, no sign of this trend here, where the PALACE floats show deep convection is clearly widespread: during the rapid convective deepening between $24 \mathrm{Feb}$ ruary and 13 March, the floats northeast and due east of the mooring experience similar water columns with convective depth differing by less than $10 \%$ despite a separation of greater than $300 \mathrm{~km}$ (float 384 sees a poorly developed convective layer because it is ejected into the boundary current). The laterally uniformity of the Labrador Sea Water itself would seem to attest to widespread convection, though this may instead be due to the efficient removal of large-scale gradients through lateral mixing ( $\$ 3 \mathrm{e})$. The situtation is further complicated by the possibility of large interannual variability in the horizontal extent of deep convection, which would seem to account for year-to-year differences in the location of finestructure across the AR7W WOCE section. Indeed, even the localization of surface heat flux, inferred from large-scale atmospheric data (as in the ECMWF heat flux in Fig. 3), has not yet been verified by direct boundary layer measurements. A clearer picture of the geography of convection will no doubt emerge from the widespread coverage of floats, moorings, hydrography, and meteorology during the 1996-98 Deep Convection Experiment.

\section{e. The postconvection response}

Following convection, the upper water column of the Labrador Sea changes rapidly. The $\theta / S$ variance decays to preconvection levels within a few months, as can be seen both in the time series (cf. Figs. 9 and 14) and on the $\theta / S$ plane (Fig.10). This is in part due to the decay of lateral finestructure: at $1000 \mathrm{~m}$ (where $\theta / S$ variance is a good indication of lateral finestructure because of the very weak vertical gradients) the standard deviation of temperature drops by nearly a factor of 3 between March and May $\left(0.072^{\circ}\right.$ and $0.027^{\circ} \mathrm{C}$, respectively). This is to be contrasted with the values during the summer and fall, which are smaller still $\left(0.01^{\circ}-0.02^{\circ} \mathrm{C}\right)$, as is evident from the size of the $\theta / S$ clouds in Fig. 10. At the same time, the water column rapidly rebounds to a warmer and more saline state, as shown in Figs. 10e,f. At the 260-m instrument, where the monthly mean temperatures vary by $\sim 0.5^{\circ} \mathrm{C}$ over the course of the year, a jump of $\sim 0.2^{\circ} \mathrm{C}$ is observed between March and May (two-thirds of which occurs between March and April).

Immediately following the end of convection, then, the Labrador Sea seems to be a mixture of cold/fresh and warm/salty water, which soon settles down into a more isopycnally homogeneous state. On the $\theta-S$ plane we can observe the transition from patches of purely convected water and nonconvected water to an intermediate water column, stably stratified in both temperature and salinity. Unless large-scale advection is important, such a transition would require both a sorting process, which creates a vertical stratification from lateral density anomalies, as well as a mixing process, which reduces the magnitude of the $\theta / S$ anomalies. The warmer, saltier properties of the final (May 1995) water column when compared to the deep convection period indicate mixing with waters that resemble the warm, saline boundary current surrounding the Labrador Sea. This could indicate either direct mixing with Irminger Water or mixing with less well-convected areas within the Labrador Sea gyre itself.

Evidence for rapid changes in the Labrador Sea following deep convection comes from CTD sections as well (Fig. 4b), which show vertical finestructure all across the Labrador Sea only a few months after convection has ceased (deep convection occurs through March; most CSS Hudson sections are occupied in May/ June). A stable stratification is rapidly formed, which can be characterized in terms of buoyancy frequency: the May 1994 and 1995 sections have a buoyancy frequency increasing nearly exponentially upward from the LSW base, with typical values of the buoyancy period $2 \pi / N$ being $3 \mathrm{~h}$ at $500 \mathrm{~m}, 4 \mathrm{~h}$ at $1000 \mathrm{~m}, 7 \mathrm{~h}$ at $1500-$ $2000 \mathrm{~m}$, and $1.5 \mathrm{~h}$ at $2500 \mathrm{~m}$. Later in the year these periods will decrease somewhat as restratification con- 

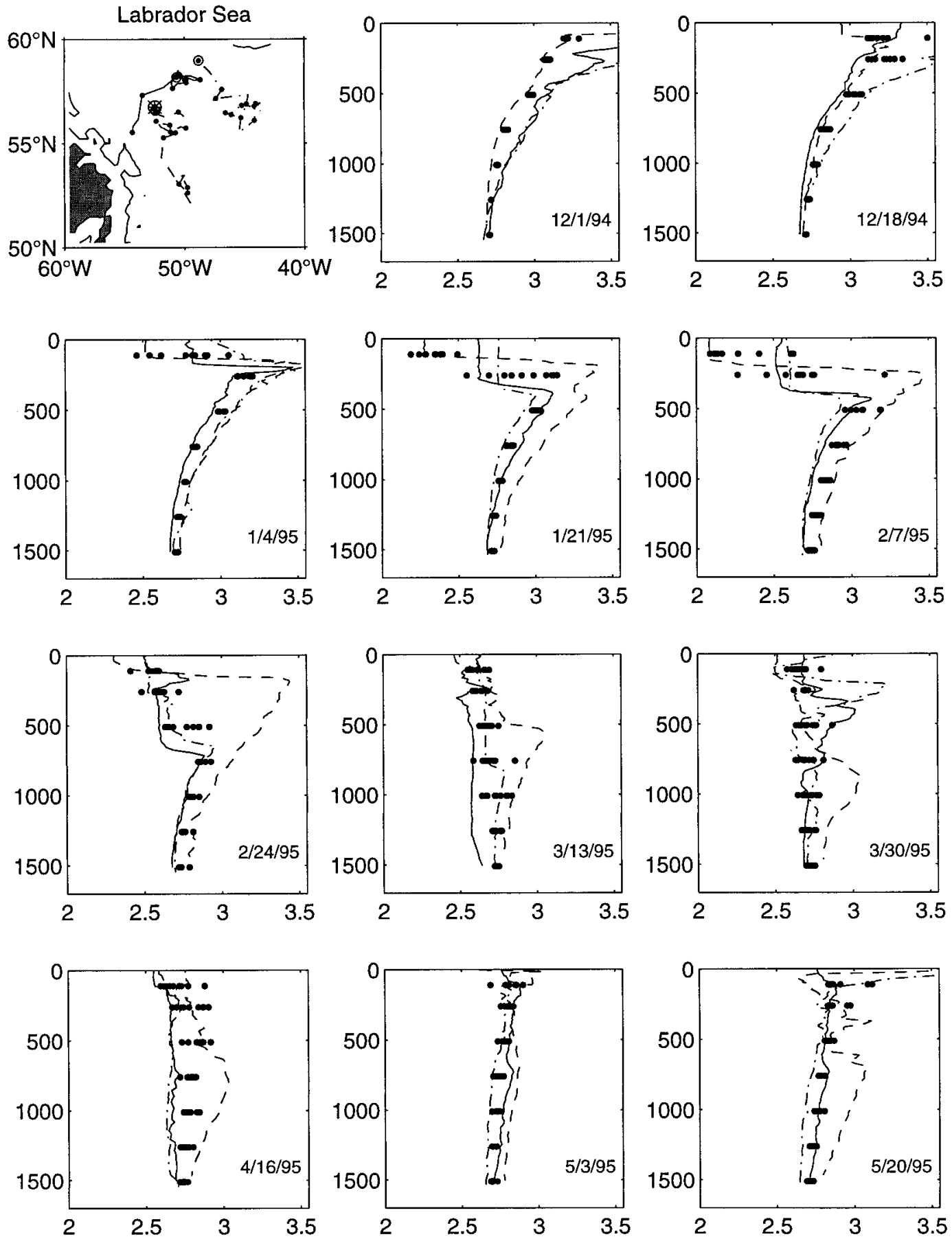

FIG. 16. Potential temperature profiles as recorded by three profiling PALACE floats and the mooring. The first panel shows the location of the floats and the mooring (star). A small dot is shown for the location of each of the following temperature profiles. The other panels show the potential temperature as a function of depth for the target date given in the lower right. The mooring data are shown as one small dot for each daily averaged temperature for a 9-day long period centered at the target date. The PALACE temperature profiles have a unique line type for each of the three floats.

tinues. This deep, surface-intensified stratification corresponds to a salinity gradient having freshwater on top, which is observed to reach down as far as $1 \mathrm{~km}$ during some years (Fig. 4b). During May 1995, for example,
CTD casts in the interior Labrador Sea show a difference of $\sim 0.025 \mathrm{psu}$ between 250 and $800 \mathrm{~m}$.

The CTD vertical finestructure and the rapid emergence of a stratification/ halocline is in part a conse- 
quence of the sorting and mixing of lateral finestructure. Such an interpretation may resolve a long-standing paradox as to the origin of the deep halocline, which has a diffusive appearance as if surface freshwater had eroded a vertically uniform salinity profile left over from deep convection. Yet this apparent freshwater entry after deep convection seems much too deep and too rapid to be explained by surface processes or by mesoscale stirring. The mooring results show instead that the formation of the deep halocline is a part of the rapid sorting and mixing following deep convection, and appears to have its origins in the lateral variablity of convection itself. Thus much of the freshwater may have been there all the time! The lateral blending of water columns that have convected to different depths quickly provides a large-scale salinity gradient as observed: laterally variable convection plus a lateral mixing process mimicks a quasi-diffusive downward mixing of $\theta$ and $S$.

After twelve months, the $\theta / S$ properties of the water column have returned remarkably close to their initial values (Fig. 10). The corresponding two hydrographic sections give us an extended look in space, and we find the deep potential temperature minimum at a nearby station to be $2.677^{\circ} \mathrm{C}$ at $2110 \mathrm{~m}$ in May 1994, and $2.675^{\circ} \mathrm{C}$ at $2220 \mathrm{~m}$ in May 1995 .

This first year's data suggests the possibility of a twophase restratification: a sudden initial phase during which lateral variations of scale between $100 \mathrm{~m}$ and 10 $\mathrm{km}$ are sorted out, and when $\theta / S$ anomalies are rapidly decaying, followed by a slow drift to warmer, more saline properties of a laterally homogenized water mass.

\section{Currents and mesoscale eddies}

The mooring is embedded in the LSW gyre, which has always been supposed to be cyclonic (e.g., Lazier 1973) based on its dynamic height field. At high latitude the barotropic mode is, however, particularly strong, and it may obscure these baroclinic tendencies. Based on the early returns from mooring and float data there is little support for cyclonic Eulerian or Lagrangian mean circulation within the gyre, despite the strong cyclonic boundary currents encircling it. Strong mesoscale eddy activity tends to obscure the means (as well as dynamically affecting them). Below we discuss the transient and mean three-dimensional velocity fields, beginning with the small convective plumes and proceeding to larger scale.

\section{a. Plumes and vertical velocity}

One of the goals of the mooring experiment was to make direct observations of convective plumes. The $\theta / S$ signal in a plume event is too small to stand out from other high-frequency activity (section 5). Direct measurements of vertical velocity, expected to be several centimeters per second, have been possible in other convective regions (Schott and Leaman 1991; Schott et al.
1994, 1996). The vertical velocity at $460 \mathrm{~m}$ for the entire record is shown in Fig. 17. The largest downward motions were recorded during late winter between midFebruary 1995 and the end of March when several convection events were captured.

Careful inspection of Fig. 17, however, shows vertical velocities of up to $4 \mathrm{~cm} \mathrm{~s}^{-1}$ during all of September and October 1994. This signal has a particular diurnal pattern and is associated with vertical migration of zooplankton. Diurnal zooplankton migration seems to be widespread in the upper ocean, and has been documented earlier by moored ADCPs in the convection region of the Greenland Sea (Fischer and Visbeck 1993) and the northwest Mediterranean (Schott et al. 1996). Plotting only the vertical velocities in excess of $2.5 \mathrm{~cm}$ $\mathrm{s}^{-1}$ against time of day and season (Fig. 18) shows that, indeed, the periods of downward motion (solid dots) correspond nicely to the time of sunrise (dashed line) and upward motion to times shortly after sunset when zooplankton migrate to their feeding horizons in the shallow euphotic zone. This signal does not reflect water velocity and hence, though interesting, it is a noise factor for our purposes. In late winter, however, the sinking events are not restricted to times close to sunrise. We still find a diurnal pattern with preferred downward motion between midnight and morning hours. If this is fluid dynamics, it is surprising, though increased shortwave radiation might inhibit daytime sinking. It may instead reflect a different mode of zooplankton behavior in the presence of convection.

Time series of heat loss, temperatures, and velocities for January-March (Fig. 19) show cold mixed layer waters reaching the sensor at $260 \mathrm{~m}$ around 15 January after a week of relatively strong heat loss (due to northwesterly winds, not shown). Despite weaker fluxes, the mixed layer temperature decreased over the next few days until 28 January when warm, stratified waters encounter the mooring. A week later, in early February, the variabililty in the $260-\mathrm{m}$ temperature increases again; this increased variance reaches $510 \mathrm{~m}$ by $10-14$ February. At the same time the high-frequency variance of vertical and horizontal velocity at $450 \mathrm{~m}$ is elevated. No dramatic downward velocity is seen, however. Convected waters did encounter the mooring, yet the convection must have occurred elsewhere.

It is only after 16 February that the two temperature sensors at $110 \mathrm{~m}$ (not shown) and $260 \mathrm{~m}$ appear to track each other closely, indicating a well-mixed layer. Because of the $\theta / S$ contrast between the upper and deep ocean, we often see density to be more well mixed in the vertical than either $\theta$ or $S$. After 16 February a series of vertical velocity events between 17 and 28 February established cold temperatures at $510 \mathrm{~m}$, with short intervals of stratification in between. Finally in early March, cold water reached $760 \mathrm{~m}$ (not shown). The largest vertical velocity was recorded during a strong cold-air outbreak, 6-7 March. From then until the end of March all four temperature sensors showed coherent 


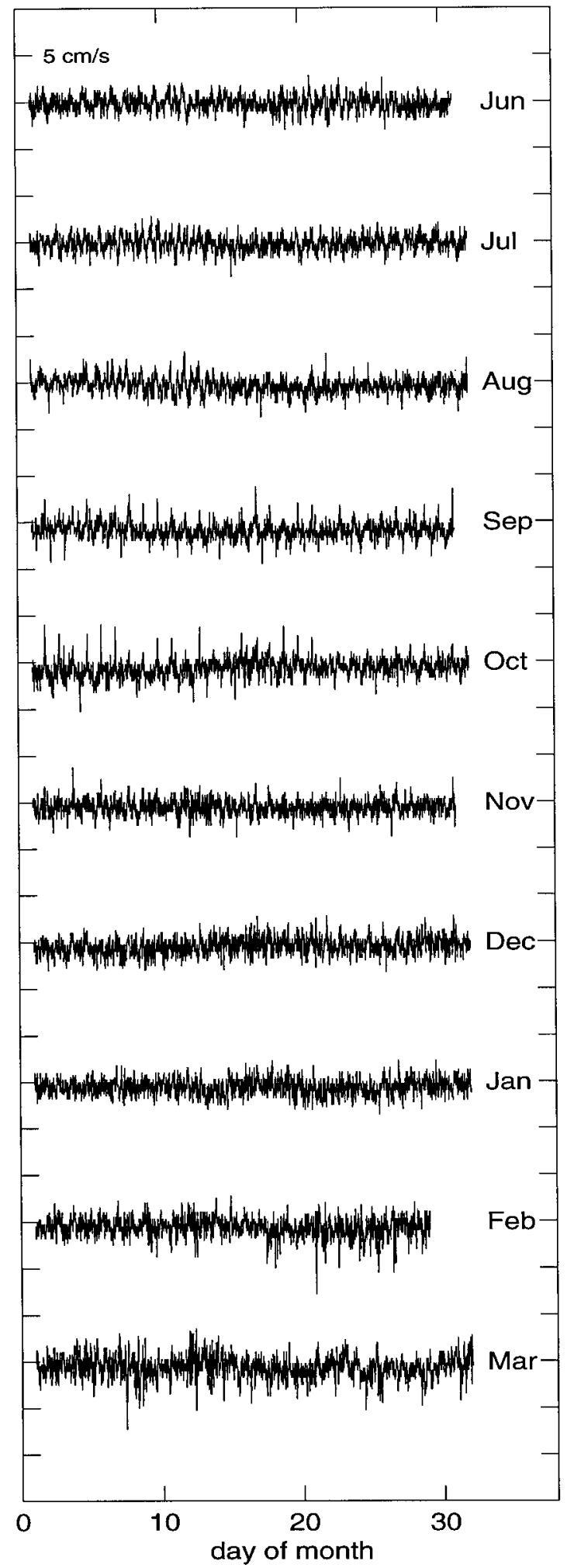

FIG. 17. Vertical velocity record with 20-min resolution from Jun 1994 until Mar 1995. Note the convection events in late winter and the diurnal plankton migration, which is at its maximum in Sep and Oct 1994.

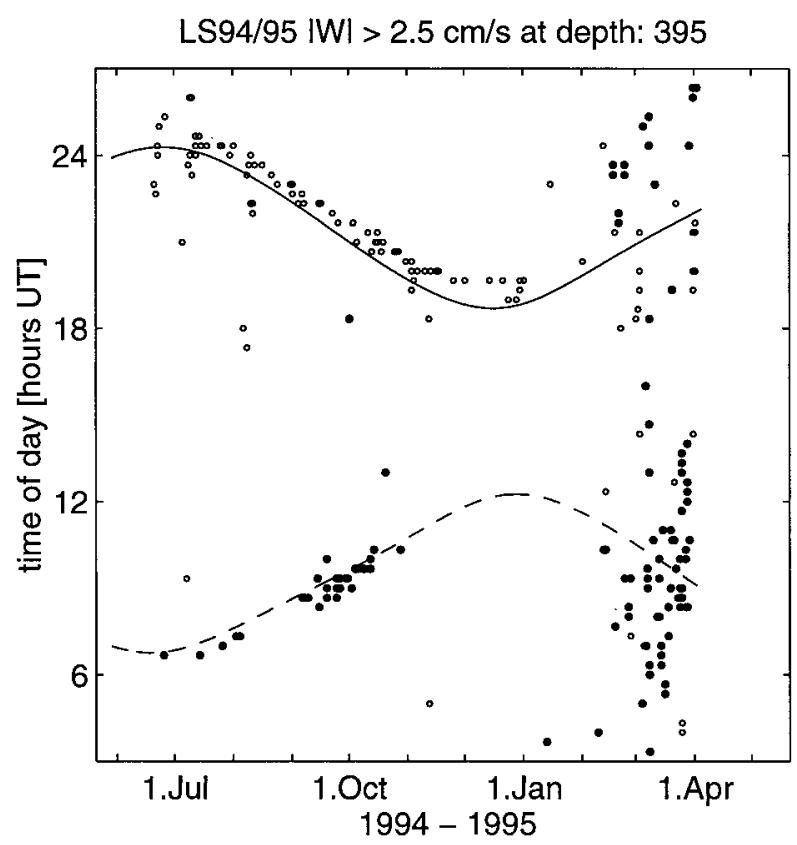

FIG. 18. Evolution of the diurnal vertical migration cycle in 400-m depth. The solid dots represent downward motion of more than 2.5 $\mathrm{cm} \mathrm{s}^{-1}$ and the open circles upward motion of more than $2.5 \mathrm{~cm} \mathrm{~s}^{-1}$. Sunrise and sunset are indicated by the broken and solid line respectively.

behavior down to $760 \mathrm{~m}$, with only brief appearance of stratified water.

With increasingly longer periods of daylight, the shortwave radiation reached about $100 \mathrm{~W} \mathrm{~m}^{-2}$ by midMarch (Fig. 19). Though this estimate is very sensitive to assumed cloudiness, the water column does seem to suffer fewer convective events at this time. In the range 300 to $500 \mathrm{~m}$ convection is apparent for about one month. We shall now look at some selected deep mixing events in detail.

\section{1) Individual CONVECTION EVENTS}

The period 20-26 February shows that coherent downward motion was observed for only very brief periods, with individual sinking events lasting less than 2 $h$. Note that the thermal stratification was variable, and large downward velocity occurred only when both 260 and $510 \mathrm{~m}$ temperatures were cold.

One prominent convection event was observed during the final hours of 22 February (Figs. 20, 21), which penetrated the entire range of the ADCP (depth 250$450 \mathrm{~m}$ ). For about $2 \mathrm{~h}$, a downward velocity of about $6 \mathrm{~cm} \mathrm{~s}^{-1}$ was seen, while the mean horizontal velocity was $7 \mathrm{~cm} \mathrm{~s}^{-1}$. If indeed the mooring encountered the plume center as it advected by, we estimate its lateral scale to be $500 \mathrm{~m}$. Veering of the horizontal velocity, after subracting the 6-h mean, shows the plume vorticity to be cyclonic. We interpret this as the upper part of a convecting plume under the influence of Coriolis forces. 

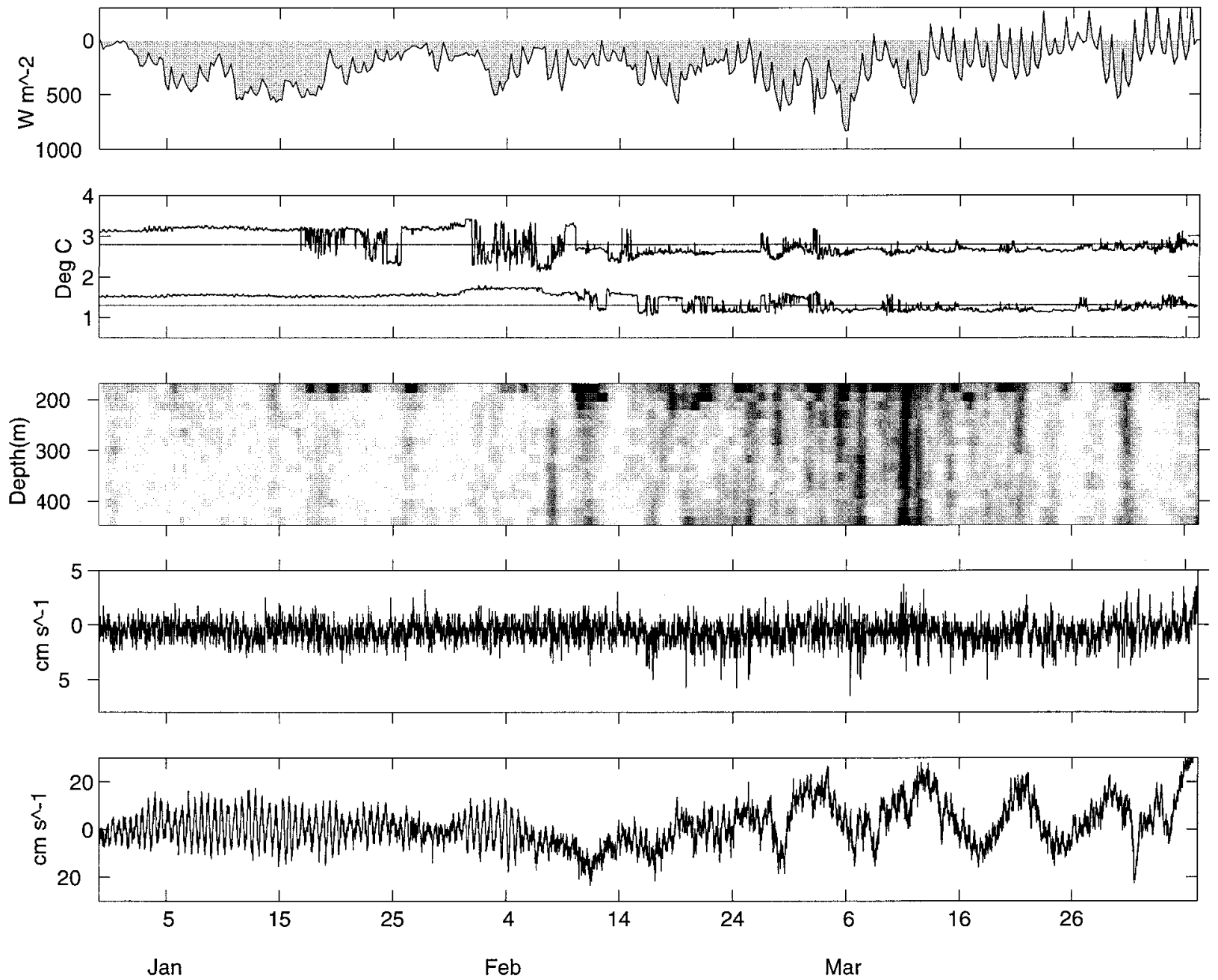

FIG. 19. (a) ECMWF total heat gain from Jan-Apr 1995 in $\mathrm{W} \mathrm{m}^{-2}$, with shading denoting heat loss. (b) Potential temperature in ${ }^{\circ} \mathrm{C}$ at $260-\mathrm{m}$ depth (upper line) and at $510-\mathrm{m}$ depth with an offset of $1.5^{\circ} \mathrm{C}$. (c) Vertical velocity variance as a function of depth and time. The variance shown is the 40-h lowpass filtered energy of vertical velocity fluctuations with a period shorter than $6 \mathrm{~h}$. (d) Vertical velocity in $\mathrm{cm} \mathrm{s}^{-1}$ at a depth of $450 \mathrm{~m}$. (e) Zonal velocity in $\mathrm{cm} \mathrm{s}^{-1}$ at a depth of $450 \mathrm{~m}$.

Laboratory and numerical simulations show similar velocity fields with sinking plumes (Jones and Marshall 1993; Maxworthy and Narimousa 1994). However, we note that the velocity field of inertial/tidal motions of large scale can appear similarly in a single Eulerian measurement, and inspection of Fig. 20 shows that indeed we have significant semidiurnal tides contributing to this event.

A second convection event occurred during the early morning hours of 25 February (not shown in detail). Downward flow lasted for a longer period and the inferred horizontal scale is larger, about $1000 \mathrm{~m}$. The horizontal velocity suggests a cyclonic event of larger amplitude. The time, near sunrise, does raise the possibility that this is a zooplankton migration.

The second period of intense activity (5-11 March, Fig. 19), followed very large heat loss from the ocean to atmosphere on 6 March. The 110-m temperature was cold but deeper layers were still warmer. Variance of vertical velocity increases without a sign of strong downwelling. This may be enhanced internal wave activity acting as a precursor to the advancing convective front, or it could be laterally advective. On the next day, $7 \mathrm{March}$, the temperature of the upper $500 \mathrm{~m}$ began to rise, consistent with penetrative convection of the advancing mixed layer base. During that apparent mixing phase the largest vertical velocity was recorded at 450 $\mathrm{m}$. This convective event with downward motion reaching $8 \mathrm{~cm} \mathrm{~s}^{-1}$ lasted longer than $3 \mathrm{~h}$. Once again, the plume occurred during daytime when zooplankton migration is possible. The horizontal diameter of the plume was approximately $1000 \mathrm{~m}$, with apparent cyclonic circulation.

From this time onward the mixed layer seemed to be well-developed and following an intense air-sea cooling on 6 March, a series of convective events were observed 

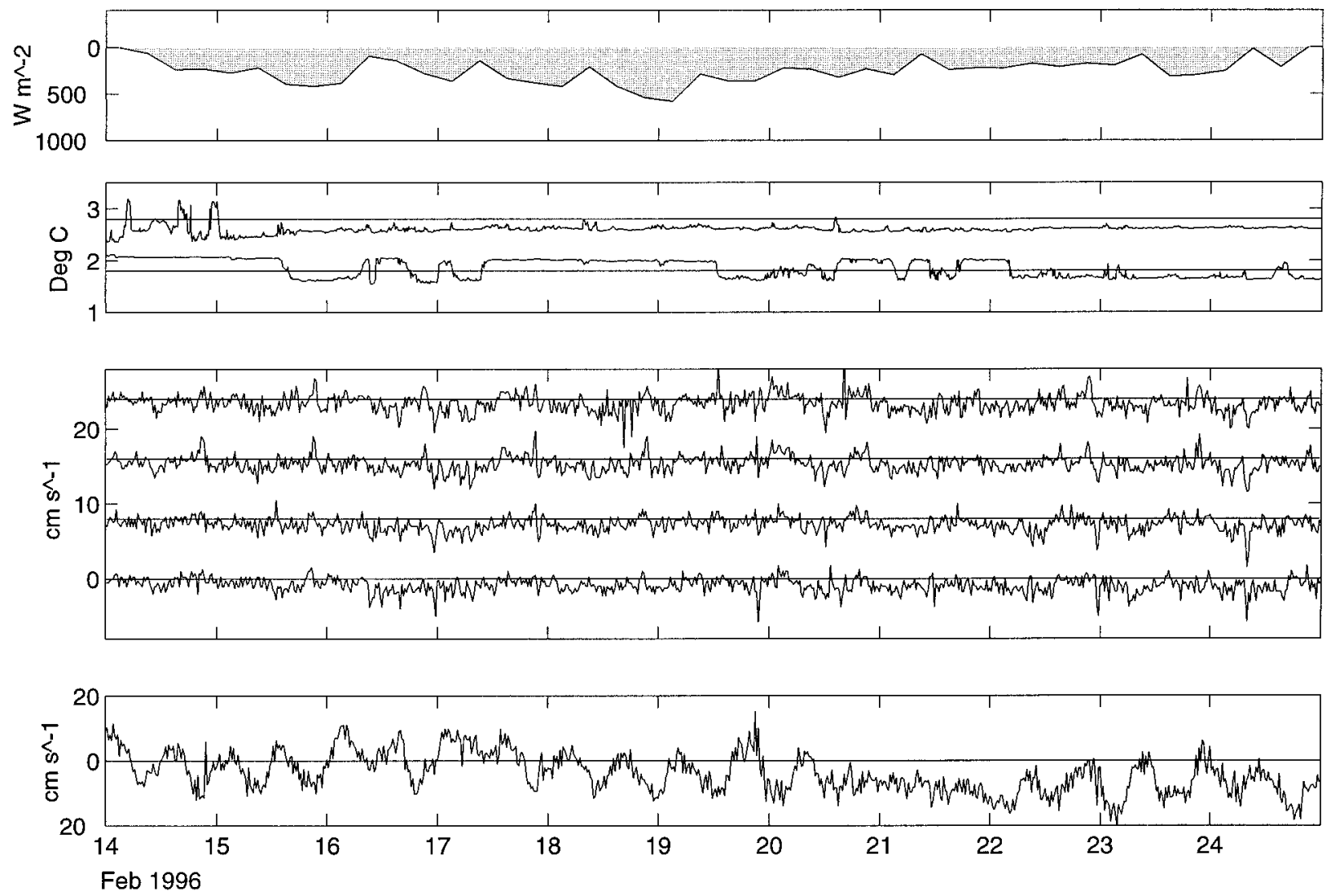

FIG. 20. (a) ECMWF total heat gain from 14 to $25 \mathrm{Feb} 1995$ (in W m${ }^{-2}$ ) with shading denoting heat loss. (b) Potential temperature in ${ }^{\circ} \mathrm{C}$ at 260-m depth (upper curve) and at 510-m depth (lower curve) with an offset of $1.0^{\circ} \mathrm{C}$. (c) Vertical velocity (in $\mathrm{cm} \mathrm{s}^{-1}$ ) depth $450,382,316$ and $248 \mathrm{~m}$. The upper curves are offset by $8 \mathrm{~cm} \mathrm{~s}^{-1}$ and each zero line is drawn. (d) Meridional velocity (in $\mathrm{cm} \mathrm{s}^{-1}$ ) at a depth of $450 \mathrm{~m}$.

during 8 March until more stratified waters encountered the mooring on 10 March. The following week began with another strong cold-air outbreak and northward horizontal ocean flow. The northward flow advected more stratified, warmer water past the mooring, judging by the increased temperature variance. The strong atmospheric forcing is accompanied by large and variable vertical velocity during the night of 12 March and morning of 13 March. The large horizontal velocity made it difficult to resolve individual plumes at the 500-1000-m scale (given the 20-min sampling interval). Yet, the characteristic downward "spiking" of the $w$ field is evident, and likely involves intense convection. Steadily increasing shortwave radiation reduced the total heat flux and for the first time warming occurred during the day.

The noise level of the instrument, combined with internal wave and zooplankton velocities, obscured convective plume activity with vertical velocities of $2 \mathrm{~cm}$ $\mathrm{s}^{-1}$ or less. In a convecting layer $1 \mathrm{~km}$ deep, such velocities would carry fluid from surface to mixed layer base in one-half day. Despite the intermittency of the really strong plumes, there may be a more continuous background of lower amplitude plumes during the 6 weeks or so of deep convection.

Significant mesoscale velocity fields exist, which affect in many ways the convection process. These are discussed in the following sections.

\section{b. Coherent eddy events}

Four coherent, energetic eddies characterized by $\sim 15$ $\mathrm{cm} \mathrm{s}^{-1}$ currents localized about an anomalous watermass core are observed at the mooring. Three distinctive anticyclones occur as well as a single cyclone. The anticyclones have the $\theta / S$ properties of relatively "pure" convectively modified water and are believed to be products of deep convection, while the cyclone's core resembles water from the Irminger boundary current. All the eddies are $10-25 \mathrm{~km}$ in diameter with currents having a middepth maximum, but the currents of the anticyclones are localized within the weakly stratified Labrador Sea Water whereas the cyclone's currents extend all the way to the bottom.

There is an interesting relationship between the density measured at $2510 \mathrm{~m}$ and the currents at $2010 \mathrm{~m}$ 

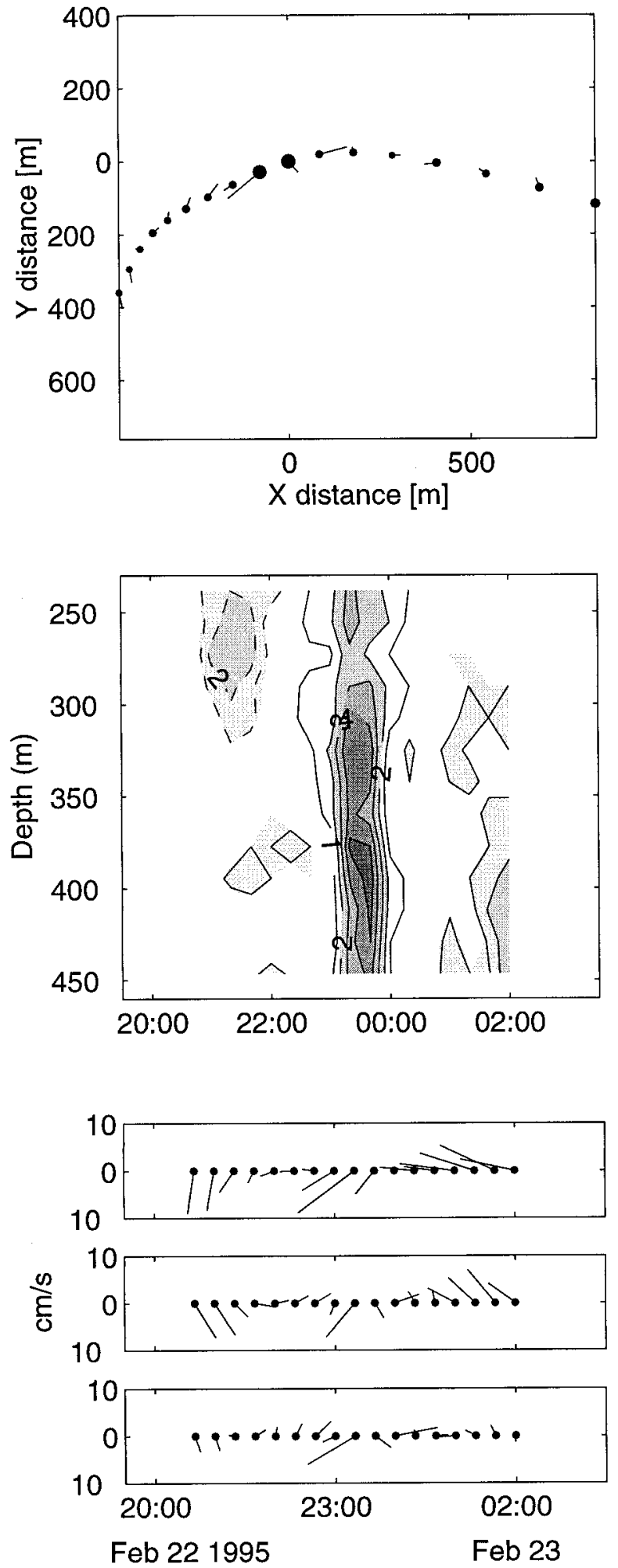

FIG. 21. (a) Progressive vector diagram computed by integrating the lowpass filtered horizontal velocities (c), with dots marking 20min intervals. The size of the dots represent the vertical velocity with thicker dots for stronger downwelling. The sticks indicate the deviation of the individual velocity measurement from the lowpass filtered timeseries (e). (b) Vertical velocity in $\mathrm{cm} \mathrm{s}^{-1}$ as a function of depth and above (Fig. 22). A correlation (though not one to one) exists between extrema of the density time series and sudden transitions in the velocity field. The $\theta-S$ plane during these density extrema shows that the 2510 -m instrument traces out the CTD $\theta-S$ profile (compare with the $\theta-S$ diagrams of Fig. 13) and therefore such events are due to vertical advection and/or towdown rather than to lateral advection. We use the pressure records to find the contribution of mooring motion to the property time series and find it to be negligible at these depths except during one major event. The density stratification beneath $\sim 2 \mathrm{~km}$ is nearly linear and changes by about $0.01 \mathrm{~kg} \mathrm{~m}^{-3}$ in $100 \mathrm{~m}$, implying that many of the density extrema shown in Fig. 22 are due to vertical excursions of the stratification of $200 \mathrm{~m}$ or more. Thus the deep stratification seems to be sensitive to small-scale velocity features in weakly stratified Labardor Sea Water above it.

Additionally, four of the events shown also correspond to anomalous water properties above $\sim 2 \mathrm{~km}$; the $\theta-S$ plane rules out vertical heaving in explaining these anomalies, so they must be advective in origin. The coincidence between the velocity, deep density, and $\theta$ and $S$ time series suggests these events are eddies that have been neatly "sliced" by the mooring, a hypothesis supported by comparing the data with a simple anayltic model of a symmetric vortex advected by a constant mean flow (Lilly 1999, manuscript submitted to J. Phys. Oceanogr.; hereafter L99). The sense of rotation can be determined either through the direction of displacement of the deep stratification (downward displacements, or density minima, corresponding to upper-layer anticyclones) or by the currents (for an anticyclone, the currents should turn first to the right and then to the left of the advecting flow). From this we find three anticyclones having cold, fresh water-mass cores and one observed cyclone with a warm and salty core.

Figure 23 shows the temperature and velocity field surrounding one of the anticyclonic eddies. A core of very cold water hovers at middepth, surrounded by currents (the component of currents normal to the advecting flow) having a maximum speed of $\sim 15 \mathrm{~cm} \mathrm{~s}^{-1}$ at the level of the core and rotating about it in an anticyclonic sense. This event is typical of the anticyclonic eddies: all have maximum velocities of $10-15 \mathrm{~cm} \mathrm{~s}^{-1}$ and currents with a similar spatial structure. Their sizes can be found by assuming they are advected by a mean flow, which yields estimated diameters of $10-25 \mathrm{~km}$.

The current structure of the anticyclones is interesting because although their water-mass lenses are localized

and time. The contour interval is $1 \mathrm{~cm} \mathrm{~s}^{-1}$ and the shading proportional to the speed. Upward flow is contoured with a dashed line and zero lines are omitted. (c) Horizontal velocity averaged over a depth range between 400 and $450 \mathrm{~m}$. (d) As in (c) with the time-averaged flow of $7 \mathrm{~cm} \mathrm{~s}^{-1}$ removed. (e) As in (c) with the 6-h low-passed horizontal flow removed. 


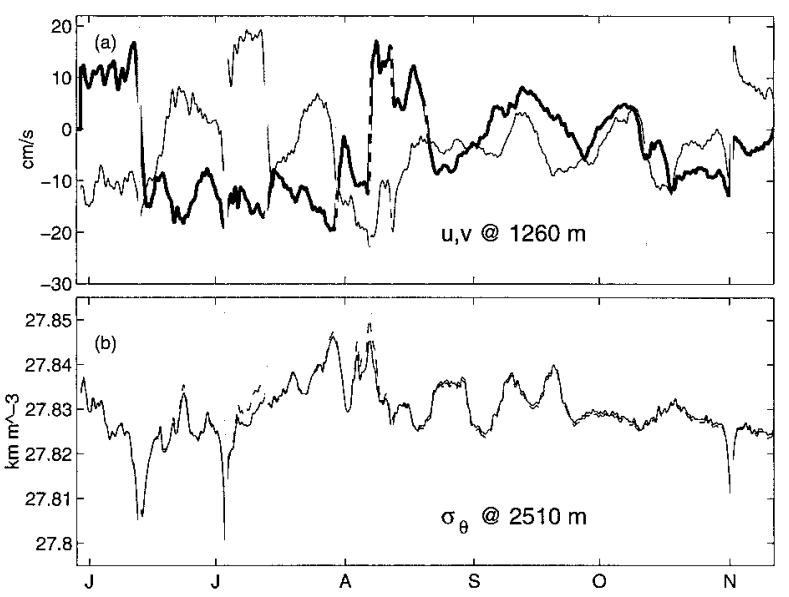

FIG. 22. (a) Time series of northward (thin line) and eastward (thick line) velocity at $1260 \mathrm{~m}$, and (b) potential density at $2510 \mathrm{~m}$ for the first six months of the mooring record. Panel (b) actually shows two curves that are nearly identical, the density corrected for mooring excursions (solid) and the uncorrected density (dashed). Gray vertical lines mark the times of sudden transitions in the velocity field (subjectively chosen); these tend to correspond with extrema in the density record, reflecting large excursions of the deep stratification. Solid lines denote those transitions that coincide with (advective) $\theta-S$ anomalies higher in the water column.

in the vertical ( $\sim 1 \mathrm{~km}$ thickness), strong currents extend from the top instrument down to $2510 \mathrm{~m}$. In this regard they are substantially different from other anticyclonic eddies, which typically have currents trapped vertically very close to the water mass core (McWilliams 1985), illustrating the unusual dynamical implications of the weak Labrador Sea stratification above $\sim 2 \mathrm{~km}$. However, virtually no signature of the anticyclones is evident at the bottom current meter. Evidently the deflection of isopycnals that makes the eddies apparent in the 2510-m density time series is sufficient to cancel lateral pressure gradients before they reach the bottom. Of course the vertical thermal wind shear gives evidence of a lateral density gradient and hence of lateral scale. This measure of lateral eddy scale supplements the determination from an assumed lateral advection speed past the mooring.

The $\theta / S$ properties of the anticyclonic eddies identify them as products of deep convection. At the time of observation, their cores are isopycnally colder and fresher than the surrounding Labrador Sea Water (see Fig. 23, inset), which is in turn colder and fresher than any other water mass in the North Atlantic. However, the Labrador Sea Water itself undergoes an annual "cycle" in $\theta / S$ space, as discussed in section $3 \mathrm{~b}$. The anticylone $\theta / S$ properties fall within the range of Labrador Sea Water in March 1995 (Fig. 13) when convection is deepest and the Labrador Sea Water is at its coldest and freshest of the year. The anticyclonic eddies appear to insulate their core water from the isopycnal warming the rest of the Labrador Sea Water undergoes; the eddy shown in Fig. 23, for example, was observed in No-

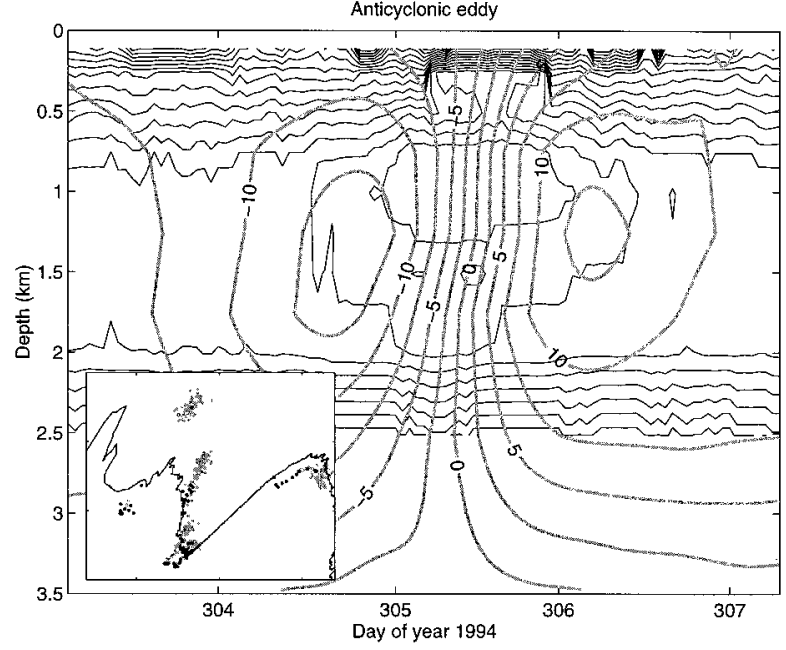

Fig. 23. Temperature contours (thin black lines) and contours of the velocity component normal to the direction of advection (thick gray lines) for a submesoscale eddy event of 1 Nov 1994. Positive velocities are ninety degrees counterclockwise from the advection direction so that the sense of circulation about the eddy core is anticyclonic. The small inset shows the $\theta-S$ diagram for times within the eddy core (black points) and the ambient water (gray points) together with the calibration cast from 1994. The eddy properties between 1010 and $2010 \mathrm{~m}$ are the coldest and freshest of the year.

vember, more than one-half year after the end of the previous winter's deep convection.

The warm cyclonic eddy (not shown) differs from the anticyclonic eddies in two major ways. While the property cores of the anticyclones are localized in depth, the core of the cyclonic eddy is anomalously warm and salty throughout the entire upper $2000 \mathrm{~m}$, with a maximum expression near the surface. Comparision with CTD casts shows the cyclonic eddy resembling water from the Irminger boundary current. Second, the currents extend all the way to the bottom, unlike the anticyclonic eddies which are damped out by the deep stratification. The estimated diameter and current speed are both comparable to the upper limits for the group of anticyclonic eddies $\left(\sim 25 \mathrm{~km}\right.$ and $\left.\sim 15 \mathrm{~cm} \mathrm{~s}^{-1}\right)$.

While only one coherent cyclonic eddy was neatly sliced by the mooring, there are several instances similiar cyclonic eddy passages that are more difficult to describe quantitatively because they are not as easily separated from the advecting flow for various reasons. As with the one well-observed cyclonic eddy, these are also surface-intensified water mass cores of Irminger type water together with a cyclonic and primarily barotropic circulation. Such features are quite common (note warm, light anomalies of upper two instruments in Figs. 9a,c), with perhaps five occuring during the restratification period. This suggests that they may be important for the transport of water properties from the boundary current into the interior, although their generation mechanism is as yet unknown.

The Labrador Sea seems to respond to the presence 


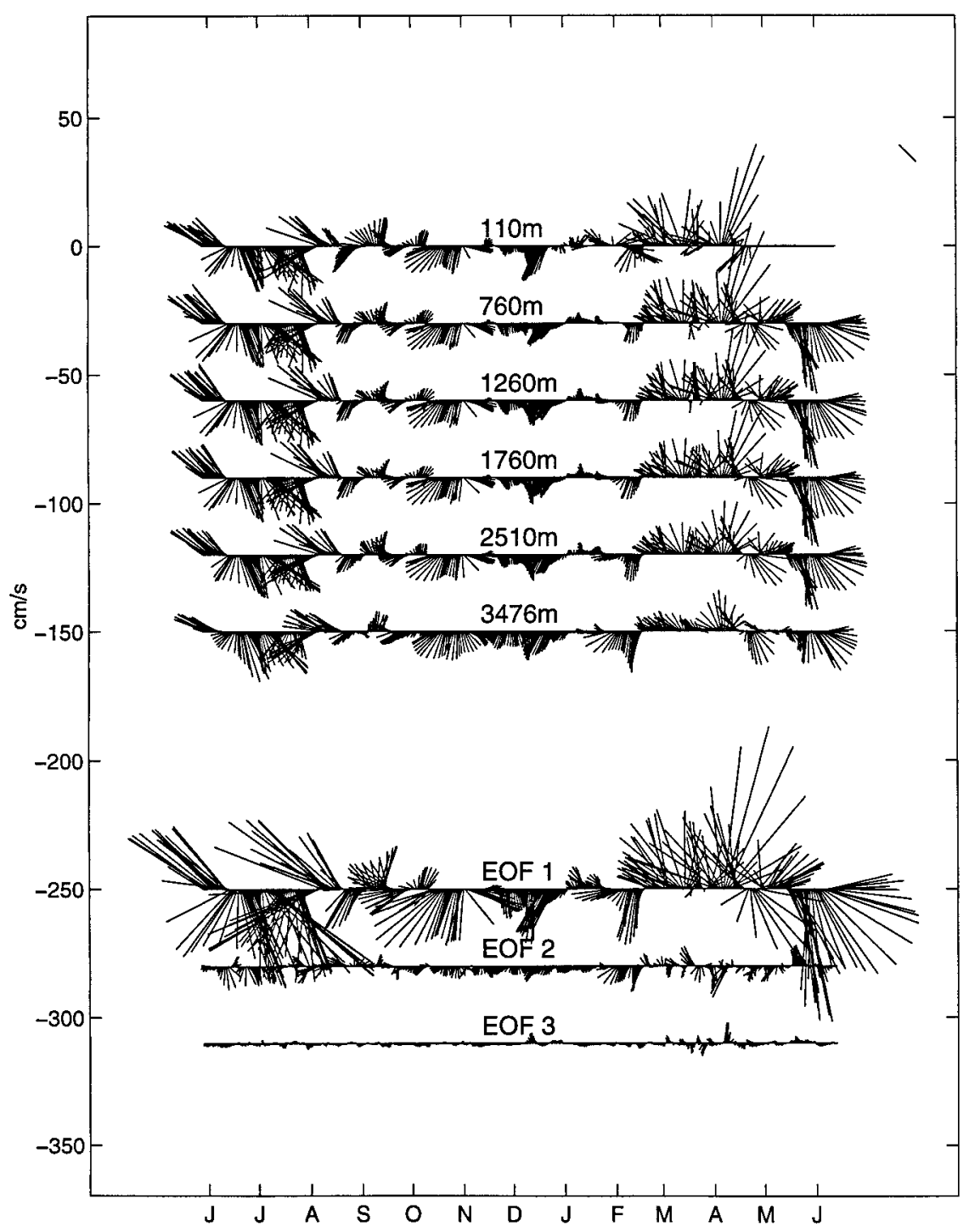

FIG. 24. Stick diagram of currents at six depths measured by Aanderaa vector averaging current meters, as well as the first three EOFs (see text for details). The hourly time series have been filtered with a 100-h Hanning filter and decimated to one point per twenty hours. Successive depths are offset by $-30 \mathrm{~cm} \mathrm{~s}^{-1}$. The water column is almost completely barotropic, though several large events are obviously surface intensified and the bottom record seems to have a slightly different character from the others. EOF 1, which accounts for over $90 \%$ of the variance, is essentially barotropic, while EOF 2 is bottom-intensified and shows a steady southward/southwestward flow.

of the anticyclonic eddies like a 11/2-layer fluid, damping out their signature within the stratified lower layer. The existence of this deep stratification may provide a Rossby-radius barrier to turbulent evolution toward large scale, as kinetic energy of the merging, expanding eddies is tranformed into eddy potential energy (Rhines 1977). The anticyclonic rotation sense is appropriate to the lower depths of a slumping chimney, and their dominance over cyclones suggests rather violent convection that drives significant deep horizontal divergence, and separates them from the shallower cyclonic convergence regions. A more detailed description of the eddy activity in the Labrador Sea is given by L99.

\section{c. Horizontal currents from the mooring and floats}

The horizontal velocity field, shown as a vector time series in Fig. 24, has energetic activity that is remarkably barotropic (depth-independent). Periods of energetic southward flow occupy much of June and July 1994, and then the kinetic energy diminishes greatly through summer and fall. In early February, at the time when convection is deepening past $500 \mathrm{~m}$, the horizontal kinetic energy rises abruptly and remains strong until early June. With currents exceeding $50 \mathrm{~cm} \mathrm{~s}^{-1}$ and a strong barotropic component, the mooring towed down $\sim 750$ 
$\mathrm{m}$ in March, destroying the uppermost Seacat/gas tension recorder and flooding the ADCP.

It is difficult to escape the feeling that the rise in kinetic energy is associated with wintertime forcing by the atmosphere and is essentially seasonal (see next section). Much longer observations will be required to answer this question, but we did find very similar, greatly winter-enhanced, seasonality in the kinetic energy during 1987/88 (Rhines and Lazier 1995).

The rms horizontal velocity was $12.3 \mathrm{~cm} \mathrm{~s}^{-1}$ at 110 $\mathrm{m}$, decreasing to $11.4 \mathrm{~cm} \mathrm{~s}^{-1}$ at $510 \mathrm{~m}$ and $9.9 \mathrm{~cm} \mathrm{~s}^{-1}$ at $3476 \mathrm{~m}$ (100 $\mathrm{m}$ above bottom). The mean velocity for the year was southwestward at $2.2 \mathrm{~cm} \mathrm{~s}^{-1}$, varying little with depth. This is not what one expects on the southwest side of a cyclonic gyre. Comparison with data not included here shows that the 1-yr means are not very stable; in none of the four years of data currently in hand is there indication of a cyclonic LSW gyre.

The spectral content of the horizontal currents involves a roughly (frequency) ${ }^{-2}$ roll-off from a broad peak that encompasses the record length (1-yr period) and the 4-month period visible in the time series; in between lies a significant $M_{2}$ tidal peak and a weaker inertial peak (14.44-h period). The low-frequency spectral peaks are of course not well defined statistically by one year's data. We note also that there is a subjective element in assessing the timescale of these currents: plots of current speed (Fig. 9d), for example, emphasize much higher frequency activity than the vector "stick" plots.

PALACE floats launched in November 1994 and May 1995 exhibit a rich set of Lagrangian trajectories (Fig. $6)$. Those launched in the boundary current east of Greenland moved rapidly along the Greenland slope, then separated and tracked more slowly southwestward toward Labrador. Note that this boundary current lies between Irminger Water above and NEADW beneath; in fact, it is most likely recycled LSW that has visited the Irminger Sea.

Palace floats in the Labrador Sea interior followed varied trajectories, from virtual stagnation to sudden ejection into the boundary current; but overall interior circulation seems remarkably disconnected from the steady cyclonic flow of the boundary currents. Float 392, launched in May 1995, "eddied" northwestward but stayed in the region for the subsequent 12 months. Float 389 remained close to its deployment location for many months until suddenly accelerating toward the Labrador coast. The long residence time of these and other floats in the Labrador Sea argues against a systematic circulation as a means of exporting LSW from the region. Other floats show even more surprising behavior: float 383, launched near the others in deep water interior to the boundary current system, unexpectedly headed southeast, passing the important topography of the Eirik Ridge (itself a sediment dune built by millions of years of boundary currents), and stagnated due south of Cape Farewell.

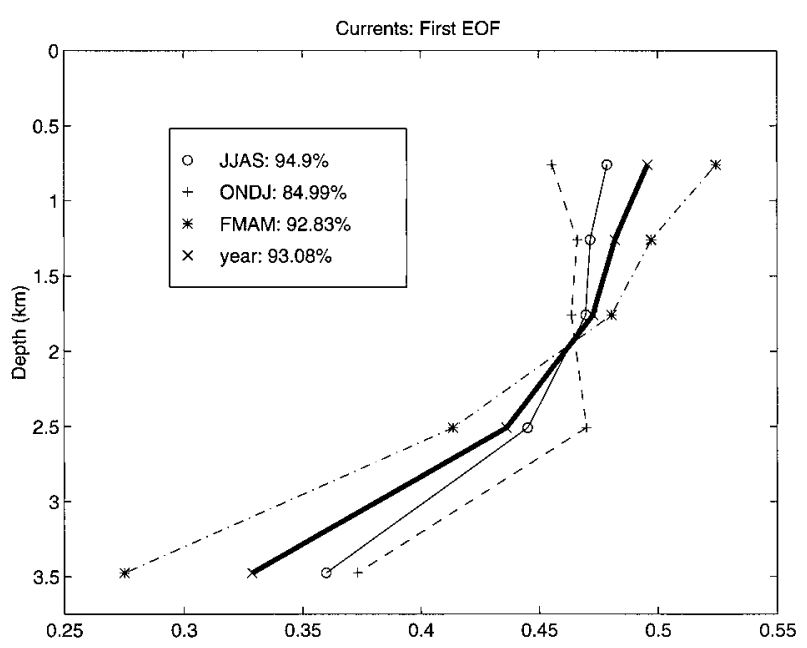

FIG. 25. Magnitude of the projection of EOF 1 onto the five instruments (the uppermost current meter was not used in the EOF definition) for the year as a whole and three four-month periods. The percent of variance explained by EOF 1 for each of these time periods is given in the figure key. Late winter/early spring (Feb-May) finds the currents at their most baroclinic.

The floats also indicate a two-way exchange between the interior and the boundary currents. Float 384, launched at the Bravo mooring in November 1994, circulated slowly until the beginning of March, when it accelerated to the south at about $13 \mathrm{~cm} \mathrm{~s}^{-1}$, joined the boundary current and sped $100 \mathrm{~km}$ southeastward, encountering the edge of the warm North Atlantic Current at the "Northwest Corner" $\left(\sim 48^{\circ} \mathrm{N}\right)$. It then moved north to $54^{\circ} \mathrm{N}$ where it sat until mid-1996. A second float (378) also escaped the LSW gyre. Launched near the mooring in May 1995, it moved (unlike float 384) northeastward, where it was engulfed in the boundary current by the Greenland continental slope. Thence it circled the sea cyclonically. In this year's dataset we saw no incursions into the gyre from the boundary current (in part because most of the floats were launched within the gyre) but they do occur in later data (Davis and Owens 1997, personal communication).

These remarkable "ejection" trajectories illustrates a new LSW "exit" mechanism proposed by Rhines and Lazier (1995), namely that pulselike behavior of the boundary currents can engulf LSW during late winter and jet it from the region. The mechanism for exchange is not well understood, but may involve the annual cycle of wind stress (and its distant signals propagated round the boundary) and of buoyancy forcing.

\section{d. Vertical structure and seasonal variability using EOFs}

The seasonal variations in the current magnitude and structure can be better expressed using empirical orthogonal functions. EOFs were computed using the complex time series $(u+i v)$ for the year as a whole 


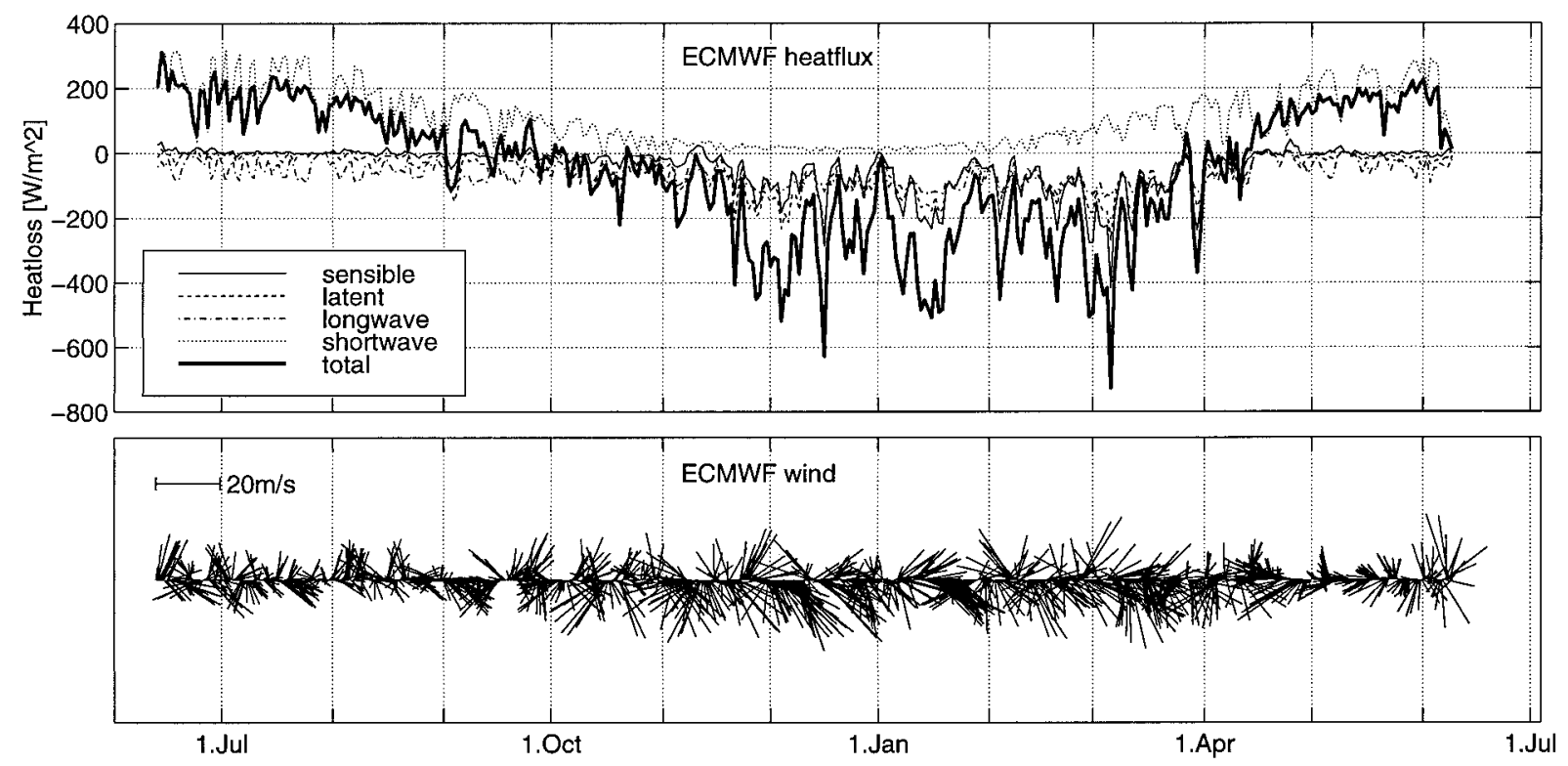

FIG. 26. ECMWF model (a) heat flux components, averaged over one day, and (b) wind stress vectors every six hours for a grid point close to the mooring over the time period Jun 1994-Jul 1995.

as well as each of the three "seasons" June-September (JJAS), October-January (ONDJ), and February-May (FMAM). The top instrument was not used since it failed in March; including it in the two earlier periods does not significantly change the EOFs.

The stucture of the modes is similiar in all four cases. The first EOF is somewhat surface intensified and is in phase at all depths, while the second EOF is bottom intensified and has a $180^{\circ}$ phase jump across the deep pycnocline (between 2510 and $1760 \mathrm{~m}$ ). We therefore interpret these two EOFs, roughly speaking, as the barotropic and first baroclinic mode, respectively.

The time series for the first EOF using the whole year's data (Fig. 24) is virtually indistinguishable from the top five current meters. The second EOF is dominated by a southwestward drift for much of the year, which in the instrument time series is swamped by the strong barotropic mode. For all four time periods considered, the first EOF dominated the variability, containing $85 \%$ to $95 \%$ of the variance, while the second mode contains $5 \%$ to $10 \%$. The third mode contains at most a few percent of the variance.

The vertical structure of the first EOF has definite seasonality, shown in Fig. 25. There is a cycle in the surface intensification, with the most "baroclinic" state of the first EOF coinciding with deep convection (FMAM). During summer (JJAS) and early winter (ONDJ), the first-mode projection is nearly uniform to $2500 \mathrm{~m}$, with the 3476-m instument being $75 \%-80 \%$ as strong as the others. However, for FMAM, the projection strength does not show such a jump at the deep pycnocline, but instead is nearly linear over the whole water column with a weaker projection at depth than during the rest of the year.
While the structure for summer (JJAS) and early winter (ONDJ) are similiar, currents during these times differ dramatically in magnitude, with ONDJ currents being about half as strong. The kinetic energy is high in early summer and late winter but lower in early winter. This energy cycle combined with the EOF variations allows the three times of year to be categorized as barotropic and energetic (JJAS), barotropic and quiet (ONDJ), and baroclinic and energetic (FMAM).

If we join together the ends of the mooring record into an annual cycle, these results suggest a pathway for the energy of the Labrador Sea currents. In the late wintertime, strong baroclinic flows are excited that by late summer evolve into (or are replaced by) barotropic flows with little change in total energy. The currents then decay to a low level but retain their barotropic character. This crude annual cycle appears to be supported by other moorings from this area, including the 1995-96 mooring at the same location and others at several nearby sites (Rhines and Lazier 1995). The evolution of a baroclinic flow field into a barotropic one is a well-understood result of the geostropic turbulence cascade to large scales, so there exists a plausible mechanism for closing the hypothesized cycle of eddy generation, barotropization, and decay.

\section{e. Possible causes of the wintertime current excitation}

There are at least four possible causes of this enhancement of wintertime currents. First, nearby boundary currents are known to have pulselike behavior and strong seasonality (Lazier and Wright 1993; Rhines and Lazier 1995). Of particular note is the enhancement of 


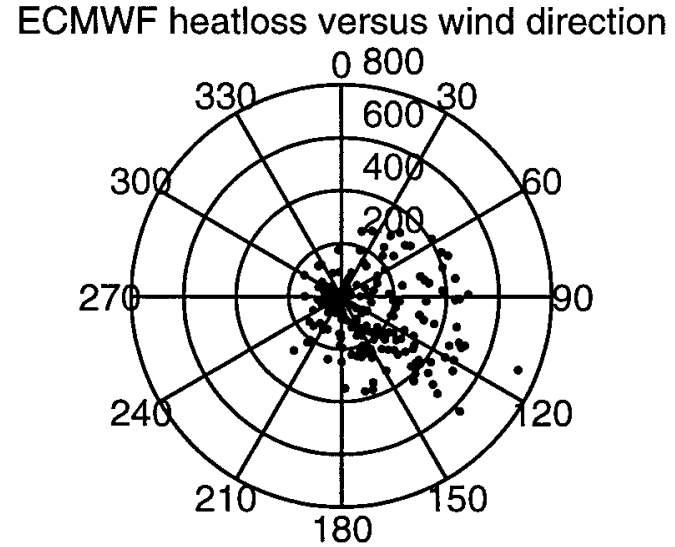

ECMWF wind stress versus wind direction

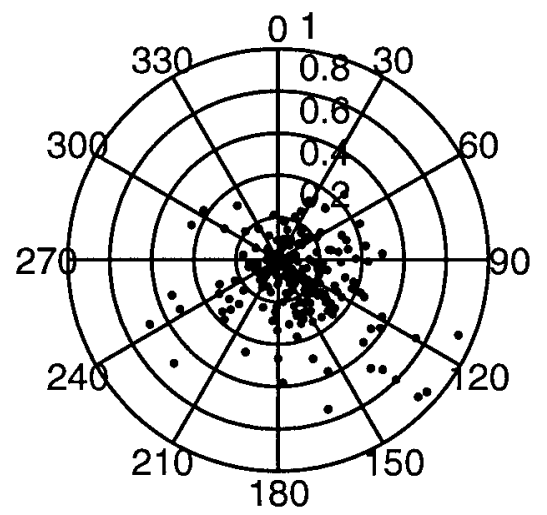

FIG. 27. (a) ECMWF net heat loss averaged over one day plotted as a function of surface wind direction for the wintertime period when the net heat flux was directed from the ocean to the atmosphere. (b) ECMWF daily averaged wind stress versus wind direction for same dates as shown in (a).

the flow at the 2500-m isobath in late winter, which Lazier and Wright (1993) associate tentatively with the spinup of the entire subpolar gyre by winter winds. Such an event might stimulate eddy energy at the Bravo site. Interaction between boundary currents and the LSW lens are crucially important to the local water-mass balances and to the export of LSW to the world ocean. After the large observational program during the winters of 1997 and 1998, much more should be known of this interaction.

A second possible cause of the pulse of wintertime energy is direct generation by winds, which become extremely strong. Barotropic response can be rapid, but estimates and models of Ekman pumping due to these winds must be refined. A wind stress of $0.2 \mathrm{~Pa}$ acting on an $f$-plane ocean for 15 days can spin up a barotropic circulation of approximate strength $\tau / \rho H \sim 7.5 \mathrm{~cm} \mathrm{~s}^{-1}$, which is strong enough to be of interest here. This estimate is simple spinup of a fluid by Ekman pumping, with negligible friction. The actual correspondence between kinetic energy and winds (cf. Fig. 26 and 24)

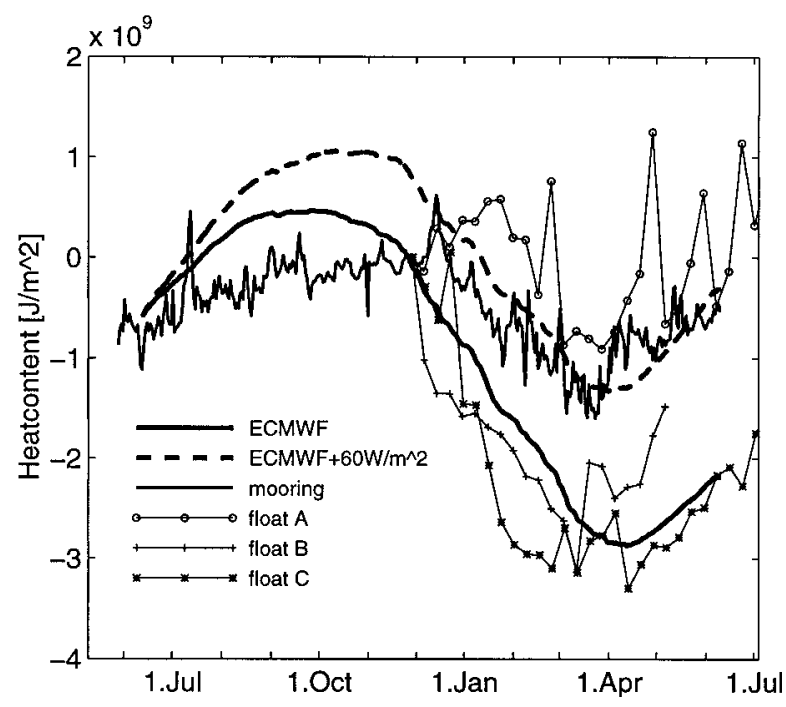

FIG. 28. Four estimates of vertically integrated heat content between Jun 1994 and Jun 1995, based on data from the mooring and from each of three PALACE floats. The bold solid line represents the time integral of the total ECMWF surface heat gain and the bold dashed line the same fluxes with the annual mean of $-60 \mathrm{~W} \mathrm{~m}^{-2}$ removed. The heat content as computed from the moored temperature sensors (solid line) was estimated by vertically integrating the observed temperatures from $1385 \mathrm{~m}$ upward and assuming that each sensor represents a layer of the thickness given by the instrumental spacing. Note that the $120 \mathrm{~m}$ deep record was assumed to represent the surface mixed layer, which is a bad assumption during the summer month. The heat content as measured by each float is indicated by symbols connected with a thin line. All curves are offset so that the heat contents match at the time of the float deployment in Dec 1994.

does not seem so supportive, however, nor does the direction of the currents bear any simple relation to the NNW winds. Estimates of wind stress show strong development in October, continuing through early April, yet the currents do not spin up until February.

This leads to a third possible cause, perhaps the favorite of this group of authors: the thermodynamic forcing of the region by surface buoyancy flux. Mesoscale currents strengthen at the time when deep convective plumes are seen. In laboratory simulations in which buoyancy forcing only occurs we find (Maxworthy and Narimousa 1994; Brickman and Kelly 1993; Rhines 1997) quite similarly that mesoscale eddies form after just a few days, and these dominate the horizontal kinetic energy from then on (though finer-scale plumes are still embedded within them). The effect is enhanced when buoyancy flux varies in space. If the water column is initially unstratified, cyclones tend to dominate the laboratory basin experiments of Rhines (1998) while convection into a stable stratification tends to favor anticyclones (also reported by Narimousa 1998). Numerical simulations (Jones and Marshall 1993) generally concur. The nature of mesoscale turbulence is particularly conditioned at high latitudes by the weak stratification and the large Coriolis frequency. The smallness of the Rossby deformation radius (typically less than 


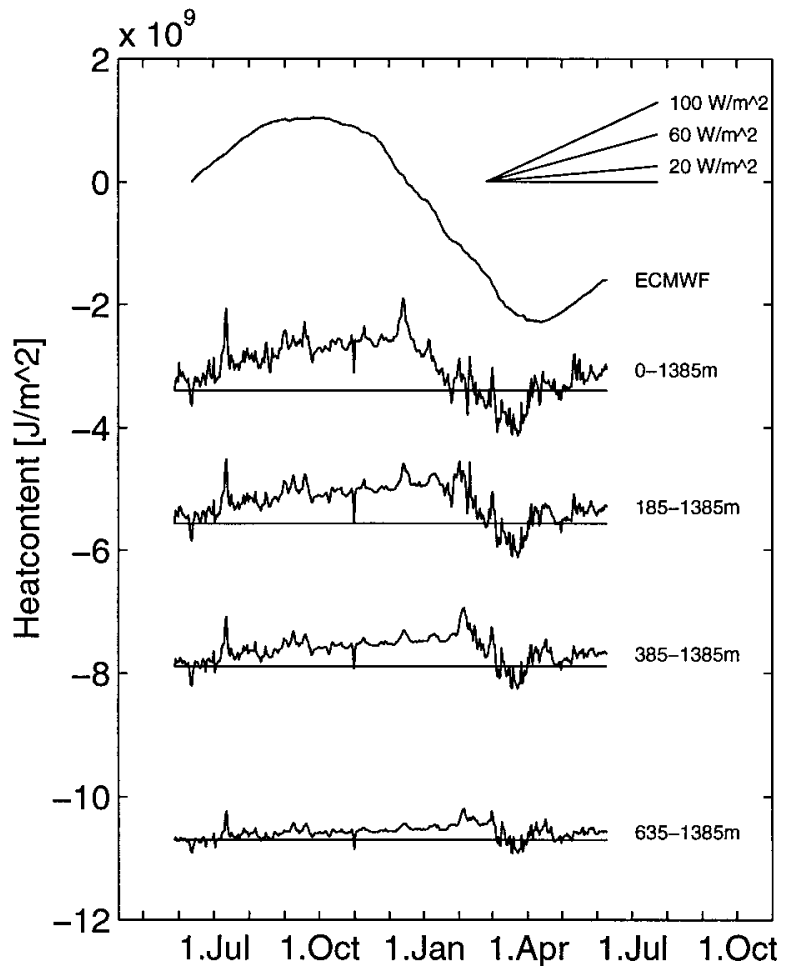

FIG. 29. Seasonal cycle of heat content from summer 1994 to summer 1995 at different depths based on the mooring measurements. The upper line represent the time integral of the total ECMWF surface heat gain. The heat content as computed from the moored temperature sensors was estimated by vertically integrating the observed temperatures from $1385 \mathrm{~m}$ upward to four different depth $(635,385,185$ $\mathrm{m}$ and the surface). Heat content changes due to different constant heat fluxes are included.

$10 \mathrm{~km}$ for the gravest vertical structure, and this is typically dominated by the stratification of the deep NEADW), indicates that the cascade from baroclinic to barotropic eddies (Rhines 1977) will be particularly effective, and it puts the convective turbulence above the 2500-m level of the NEADW not far from the "homogeneous fluid" limit.

With substantial energy apparently tied up in a northward flow for two months followed by southward flow for four months (treating the record as periodic), we must mention a fourth possible explanation. Seasonal wintertime acceleration and subsequent relaxation of the gyre-scale circulation involving the LSW lens, due either to wind stress or buoyancy forcing, could account for the rather low frequency of the observed currents. We do not presently favor this explanation because observations from 1987-88 did not show the same orientation or low frequency of the winter-enhanced currents.

\section{Column heat balance and winds}

Since 1974 when OWS Bravo was abandoned (Lazier 1980), the present work is the first attempt to measure the full cycle of thermal stratification in the central Labrador Sea. Figure 16 compares temperature profiles from PALACE floats with the nine moored sensors between 120 and $2000 \mathrm{~m}$, repeating the information in Figs. 8 and 9a. Depending on float location there is a more or less developed layer of warm Atlantic water in the upper $400 \mathrm{~m}$ into which the cold surface mixedlayer waters penetrate. The deepest penetration of the cold water was found between mid-March and midApril, extending beneath $1000 \mathrm{~m}$.

The surface heat loss close to the site of the mooring, as predicted by the ECMWF model shows a net heat loss to the atmosphere between October 1994 and April 1995 to average $207 \mathrm{~W} \mathrm{~m}^{-2}$ (Fig. 26). The annual average heat loss from summer 1994 to summer 1995 was $51 \mathrm{~W} \mathrm{~m}^{-2}$, compared with the mean heat loss over 1949-74 estimated by Smith and Dobson (1984) of 28 $\mathrm{W} \mathrm{m}{ }^{-2}$. These authors point out that use of Bunker's coefficients, which produce smaller shortwave heat gain and larger sensible and latent heat losses, would predict a much larger annual mean heat loss to the atmosphere of $98 \mathrm{~W} \mathrm{~m}^{-2}$. During periods of strong northwest winds, however, the sensible heat exceeds $300 \mathrm{~W} \mathrm{~m}^{-2}$, and total upward heat flux, daily averaged, can exceed $700 \mathrm{~W}$ $\mathrm{m}^{-2}$. Heat flux is enhanced during periods of west or northwest winds (Figs. 26, 27).

The time integral of the heat loss computed from ECMWF data is compared to the vertically integrated heat content $(0-1350 \mathrm{~m})$ as recorded by moored sensors and the profiling PALACE floats (Fig. 28). Neither the Lagrangian trajectory of the floats nor the fixed Eulerian measurement from the mooring follows the heat balance of a column of water. Float B, some $150 \mathrm{~km}$ north of the Bravo mooring seems to track the ECMWF heat flux well between January and March. Float A shows significant warming as it moves southward closer to the continental rise, with strong fluctuations possibly reflecting mesoscale features. Float $\mathrm{C}$, however, drifts southeast and rapidly "loses" heat. In the succeeding month the observed heat content more or less tracks the expected warming due to shortwave radiation.

Unfortunately the mooring record misses the top 120 $\mathrm{m}$ of the water column, and with it the summer heat content. Comparison with ECMWF requires a model of the upper-ocean heat storage. If we consider just the period from mid-December to mid-April, when the heat content in the upper $120 \mathrm{~m}$ is changing little, the agreement between mooring and meteorological data is satisfactory. However, for the LSW to be in a relatively steady state over one year, there must be a lateral import of heat to balance the net $60 \mathrm{~W} \mathrm{~m}^{-2}$ observed to leave through the sea surface. This suggests adding $60 \mathrm{~W} \mathrm{~m}^{-2}$ to the ECMWF curve on Fig. 28 (dashed curve), which does improve the agreement during December through April. The assumption here is that the lateral warming by eddy mixing occurs steadily throughout the year.

This lateral influx of heat can be examined by plotting heat content integrated through various layers of the 
(a)
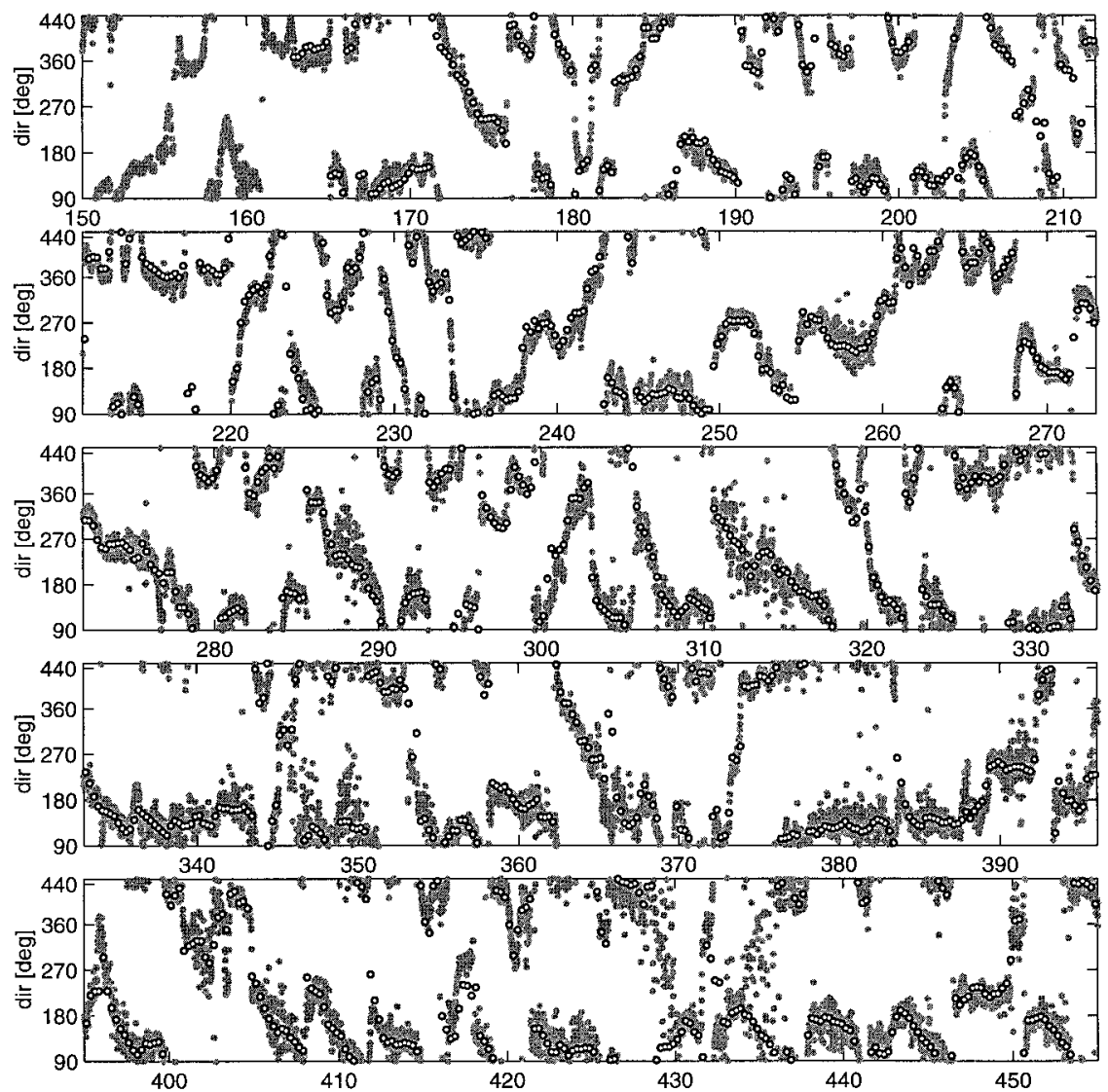

FIG. 30. Panel (a) shows ECMWF wind direction (solid dots) and ADCP surface Doppler direction (open circles) for the period between Jun 1994 and Mar 1995.

water column (Fig. 29). It becomes apparent that heat is supplied laterally throughout the the upper $1000 \mathrm{~m}$. For example, the heat content below $400 \mathrm{~m}$ is still rising, despite surface cooling, from October through January. The rates of warming of the layer $200-1400 \mathrm{~m}$ correspond to a surface heat flux of about $30-40 \mathrm{~W} \mathrm{~m}^{-2}$, or more than one-half the required heat flux. This suggests that the other half enters laterally between the surface and $200 \mathrm{~m}$.

Wind vectors show a number of storm events that intensify in fall and winter. The upward looking ADCP on the mooring allows us to estimate wind direction using the sea-surface Doppler signal (Schott 1989; Visbeck and Fisher 1995). The comparison with wind direction from ECMWF is striking (Fig. 30a). The 20min resolution of the ADCP connects with the 6-hourly ECMWF wind directions almost perfectly. Only on days $288,348,429$, and 435 was there substantial disagreement, when wind speeds were large. We attribute the difference to loss of the Doppler signal during wavebreaking events.

Wind speed was inferred from ambient sound recorded by the WOTAN (Vagle et al. 1990) and these compare well with the ECMWF model, once an empirical amplitude fit is made (Fig. 30b). The overall correspondence between ECMWF and the mooring is surprisingly good and lends confidence to both.

\section{Conclusions}

A combination of Eulerian and Lagrangian techniques is now being applied to the convection and circulation of the Labrador Sea. The mooring and PALACE floats, with their dense time and vertical coverage, respectively, complement traditional hydrographic sections. The region is important across the spectrum of scales from small-scale water-column physics and mixed layer dynamics to mesoscale eddies, basin-scale circulation, global meridional overturning, air/sea buoyancy flux, and climate. Not the least of our hopes is to contribute to more accurate numerical circulation models.

The cycle of convection and restratification in the Labrador Sea during May 1994 to June 1995, a year with moderately intense wintertime cooling (averaging about $300 \mathrm{~W} \mathrm{~m}^{-2}$ ), has been observed at a single mooring sited along a line of annually repeated hydrographic 
(b)
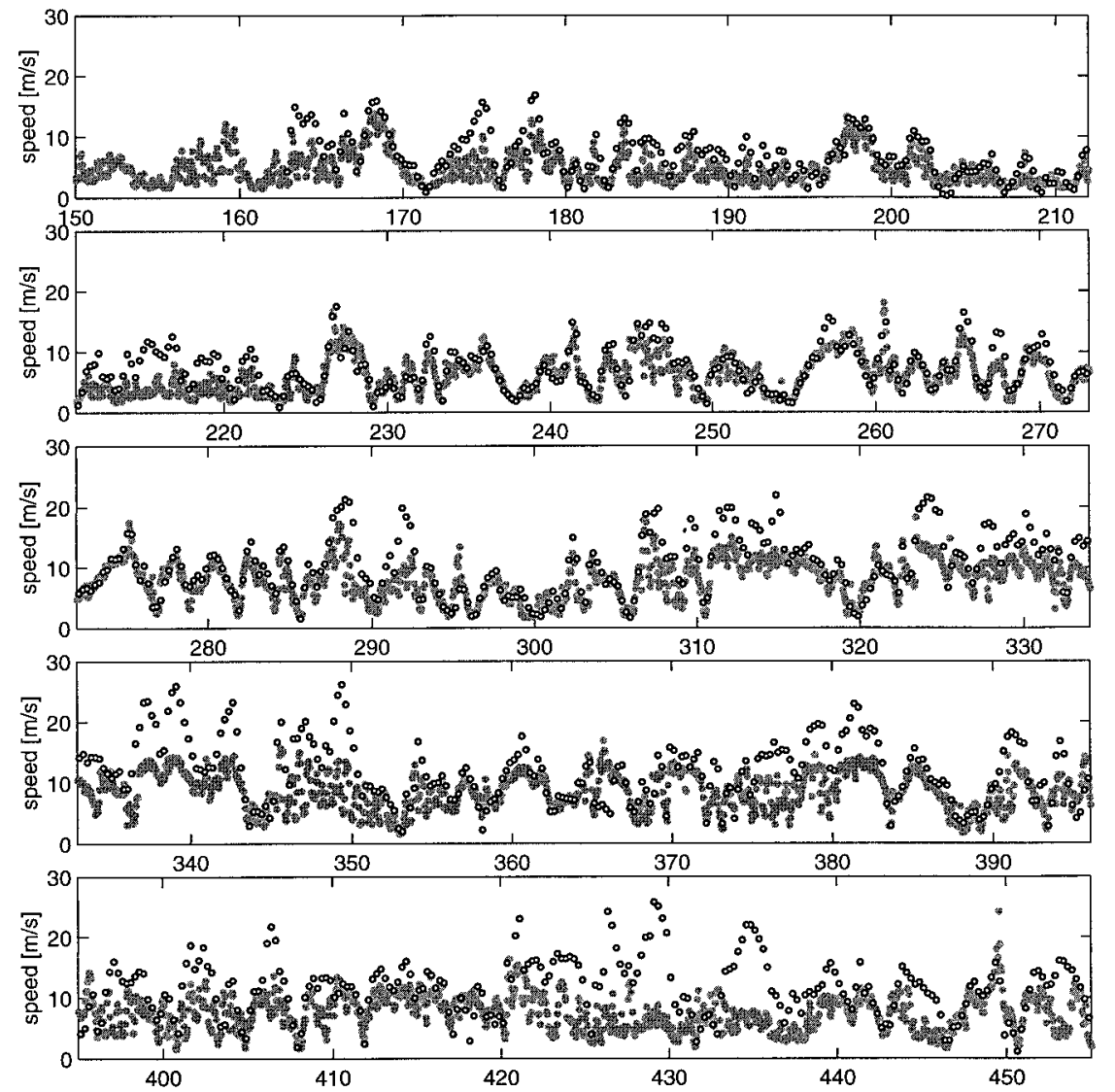

FIG. 30. (Continued) Panel (b) shows ECMWF wind speed in $\mathrm{m} \mathrm{s}^{-1}$ (solid dots) and inferred from the WOTAN passive acoustic device on the mooring (open circles) for the same time period.

measurements, as well as by profiling PALACE floats. We have continued deployment of the mooring into its fourth year at the time of this writing. The perspective afforded by several years' data shows great interannual variability, with the years 1992-95 marked by strong convection and later years by sporadic convection and relaxation toward a warmer, more saline, more stratified state.

Deep convection in the Labrador Sea is thermally driven, transporting low-salinity upper waters downward to a depth of about $2 \mathrm{~km}$, which mix with the higher salinity Labrador Sea Water $\left(\theta \sim 2.7^{\circ} \mathrm{C}, S \sim\right.$ $34.83 \mathrm{psu}$ ) and the yet higher salinity and temperature NEADW beneath. While the Labrador Sea is moderately small and its contribution to the global poleward heat flux is not large $[\sim 0.2 \mathrm{pW}$ wintertime air-sea heat flux, and much less than this $(\sim 0.04 \mathrm{pW})$ for the annual average], it is nevertheless one of the dominant sources of low-salinity water for the middepth $(1500 \mathrm{~m})$ World Ocean. Through entrainment into the DSOW, it also affects strongly the abyssal circulation. Potential energy (PE) generation is more significant here than in subtropical regions of comparable heat flux, for PE creation varies directly with the depth of penetration of the cooling. For example, cooling uniformly a layer of depth $h$, so that its density changes by an amount $\delta \rho$, causes the potential energy change $\delta\left(\frac{1}{2} \rho g h^{2}\right)=-\frac{1}{2} h[g h \delta \rho]$, the bracketed quantity being the total buoyancy change per unit surface area.

Deep convection is accompanied by intense, highfrequency fluctuations of temperature and salinity. This is the result of low-salinity surface waters being cooled below the temperature of the deep water until they convect and are advected past a fixed mooring. The $\theta / S$ richness of the water column persists following the end of convection, suggesting lateral inhomogeneity. Such variability, which has a large dynamically passive component, undergoes a tracer cascade to high wavenumber and final dissipation. The degree of density compensation increases at high frequency and increases at the time of active deep convection. Temperature and salinity spectra roughly vary as (frequency) ${ }^{-2}$.

Restratification after convection in quiet years is as important as convection itself. We give at least a partial resolution of the paradoxically rapid appearance of a stratified, deep-reaching "lid" of low-salinity water. 
This seems to arise not principally from invasion from the sides of the sea, but from the spatially variable depth and/or properties of the convective mixed layer. The ocean is left in early spring with a strong upward-decreasing salinity profile shortly after convection, which has the appearance of a freshwater near-surface input diffusing downward, rather than convection producing a vertically homogeneous water mass. At most depths beneath the summertime mixed layer we found salinity, temperature, and buoyancy to increase with time throughout the nonconvecting majority of the year. On all isopycnals under observation (between 250 and 2010 m) salinity increases during restratification, constraining the freshwater source for the convectively formed Labrador Sea Water to be very near the surface.

The subsurface restratification provides an independent estimate of air-sea heat flux during wintertime convection. The cycle involves about $4 \times 10^{9} \mathrm{~J} \mathrm{~m}^{-2}$ of cooling during October through April $\left(207 \mathrm{~W} \mathrm{~m}^{-2}\right.$ averaged over these months). About one-half of the annual heat storage is in the upper $100 \mathrm{~m}$.

Acoustic Doppler measurements of vertical velocity show intense plume activity during the convection season. Downward vertical velocity of 4 to $8 \mathrm{~cm} \mathrm{~s}^{-1}$ and plume diameters 200 to $1000 \mathrm{~m}$ are observed intermittently. Despite this intermittency, convective vertical velocities below the ADCP noise threshold may be occuring more continuously during the winter season.

Coherent submesoscale eddies occur of two distinct types. Anticyclones with cold, fresh cores are the direct product of deep convection but differ from the eddy types predicted by numerical models and theory. These cold anticyclones contain convected water that is insulated from the isopycnal warming and salinization that the rest of the sea undergoes during the nonconvecting part of the year. Warm, saline, cyclonic eddies whose cores have the properties of Irminger Water from the boundary current also encountered the mooring.

In general, the horizontal velocity field has a strong barotropic component, largely mesoscale in nature, which is excited along with a substantial baroclinic component as convection deepens to $1000 \mathrm{~m}$. Its mean over six depths is $2.2 \mathrm{~cm} \mathrm{~s}^{-1}, 232^{\circ}$ true, and standard deviation of $11.8 \mathrm{~cm} \mathrm{~s}^{-1}$. PALACE float trajectories and other mooring data show that this mean is not completely stable, and that internal circulation of the Labrador Sea Water is strongly affected by eddy processes. There is no sign of a cyclonically rotating LSW gyre once one is seaward of the cyclonic boundary currents; if anything the Eulerian and Lagrangian means suggest a weak anticyclone. The floats show a remarkable variety of behavior involving long periods of confinement in the central Laborador Sea, but also rapid ejection via boundary currents. The eddy field may be the consequence of the convection (as seen in laboratory and numerical experiments), although wintertime intensification of nearby boundary currents cannot be ruled out as a cause. If these year-long observations are indeed respresentative, then the annual cycle of the currents is one of wintertime energization, followed by barotropization, interaction with boundary currents, and finally decay.

Deep convection cannot be understood in isolation: basin-scale hydrography and circulation set the stage. Low-salinity runoff, ice melt, and precipitation at the top of the water column on the one hand, and warm, saline subsurface Irminger Water flowing into the region from the subtropics, on the other, provide the end points for the wintertime heat loss-driven overturning. We do not yet know the sources of the low-salinity water that make the upper ocean so buoyant and have caused the salinity of all the major subpolar Atlantic water masses to decline for the past 30 years. Interannual variability of these sources may be the dominant oceanic source of LSW climate variability, yet we know much more about the air-sea heat transport than about the sources and sinks of freshwater and salt.

Acknowledgments. R. Davis is supported by NOAA through the Consortium on the Ocean's Role in Climate; D. Farmer by the Department of Fisheries and Oceans, Canada; and J. Lazier by the Department of Fisheries and Oceans, Canada. P. Rhines and J. Lilly are supported by the Office of Naval Research, and a DOD graduate Fellowship. The Bravo mooring was first funded by NOAA-Atlantic Climate Change Program, with contributions from the Office of Naval Research. M. Visbeck is supported by the Office of Naval Research and F. Schott by Deutsche Forschungsgemeinschaft, Grant Scho/168/24-1. We thank the skillful and dedicated personnel of the CSS Hudson and the staff of Bedford Institute of Oceanography for carrying out so much of the work reported here. We also thank I. Yashayaev for supplying Fig. 2, R. A. Clarke for the data used in Fig. 11, and A. Sy for the Meteor data used in Fig. 13.

\section{APPENDIX A}

\section{Seacat Calibration}

Calibration was challenging owing to a number of factors. Lateral and vertical finestructure hindered comparison with calibration casts, and towdown due to strong barotropic velocites led to instrument pressure excursions, which affected the salinity and density computations from conductivity. Futher, the signal-to-noise ratio was low, with the range of salinity fluctations during most of the year $(\sim 0.01 \mathrm{psu})$ being comparable to the instrument accuracy claimed by Seabird. We found onshore calibrations not to be particularly useful, but had good results calibrating the instruments against the calibration casts once the pressure history at each instrument was accurately estimated. Because much of the variability at the mooring was due to the profiling of vertical finestructure, we found it important to compare 
the mooring measurements with the calibration CTD casts in both $\theta / P$ and $S / P$ as well as $\theta / S$ plots.

\section{a. Construction of pressure records for all instruments}

Depth levels of instruments described here are nominal; more precise values of the 16 depths in Fig. 7 are $110,112,130,170,280,510,528,776,1015,1273$, $1520,1767,2014,2509,2511$, and $3460 \mathrm{~m}$. The algorithm for determining $S$ from $C, T$, and $P$ is sensitive enough to pressure that the occurence of large mooring excursions significantly contaminated the salinity values (and therefore the density) if a constant pressure was used. An increase of pressure of $20 \mathrm{db}$ corresponds to a decrease in salinity of $0.01 \mathrm{psu}$, which is as large as the variability during the nonconvecting part of the year. Care must therefore be taken to estimate the pressure at each instrument as precisely as possible.

Pressure was measured at two depths, 110 and 1010 $\mathrm{m}$. To estimate the pressure at the other instruments a simple mooring model was used, which together with coefficients for the drag and buoyancy of each mooring component determined the equilibrium response of the mooring to a given velocity profile. Using the measured velocities (interpolated between gaps in the vertical) in this model gives an estimate pressure record for all depths that does not rely at all upon the measured pressures. The difference between the modeled pressure and the measured pressure at 110 and $1010 \mathrm{~m}$ is often less than $2 \mathrm{db}$, although long pulses of 10-20 db and larger error still remain.

The mooring model can be improved by imposing a correction of the form

$$
\begin{aligned}
P(z, t) & =\tilde{P}(z, t)+a(t) \delta \tilde{P}(z, t) \\
\delta \tilde{P}(z, t) & \equiv \tilde{P}(z, t)-\tilde{P}_{o}(z),
\end{aligned}
$$

where $z$ is the position of a given instrument on the mooring, $P(z)$ is the measured pressure at location $z, \tilde{P}$ is the modeled pressure, and $\delta P(z, t)$ is the departure of $\tilde{P}$ at depth $z$ from its resting pressure $\tilde{P}_{o}$. Essentially we are looking for corrections to the model pressure excursions that are proportional to the excursions themselves, with a proportionality factor of $a(t)$ which may be solved at each measurement time. Solving the above equation for $a(t)$ using the 1010-m pressure record, we find the error between the corrected model and the other $(110 \mathrm{~m})$ pressure record is reduced to pulses of 5-10 $\mathrm{db}$. However, the mooring model is based on static response and tends to systematically lag the data, resulting in large errors at high frequencies. When the time series is lightly filtered to remove the tides the error is decreased further, becoming less than $\sim 5 \mathrm{db}$ at all times, which is more than adequate for our purposes.

\section{b. $\theta$ and $S$ calibration}

Instrument calibration for $\theta$ and $S$ was done after the pressure had been correctly estimated so that any $S$ error resulting from uncertainty in the resting instrument depth would corrected for. Because for small changes the equation of state is linear, calibrating $\theta$ and $S$ is equivalent to calibrating $T$ and $C$, but the former turned out to be much simpler, for example, because then the $S$ corrections are determined independently from the $T$ corrections.

First, constant offsets were determined for $\theta$ by comparing $(\theta, P)$ plots from the mooring with the three calibration CTD casts. It was assumed that there is no significant drift in temperature sensor, based on information from Seabird that the sensor drift at most $\sim 0.002^{\circ} \mathrm{C}$ per year. Constant offsets for salinity were then determined using the two deployment casts, and then matching the mooring data to the recovery cast yielded a linear drift. Calibrating the salinity turned out to be difficult, owing to the expected importance of drift and to the vertical and horizontal finestructure. We attempted to match the mooring to the calibration casts using $\theta-S$ diagrams as well as $\theta-P$ and $S-P$ plots. The $\theta-S$ comparisions allowed for finer calibration because the vertical profiling of intrusive structures created large $S-P$ and $\theta-P$ scatter, which seemed inconsistent with the CTD casts but which traced out features of the CTD casts in $\theta-S$ space. The calibrations could then be checked by verifying that $\sigma_{0}$ computed from the mooring $\theta$ and $S$ also matches the CTD casts.

The final corrections applied to the six Seacats were as follows: $\theta$ offset, $\left[\begin{array}{llllll}0.01 & -0.02 & -0.01 & 0 & 0 & 0\end{array}\right]^{\circ} \mathrm{C} ; S$ offset at the beginning of the record, [0.0085 0.0070 $0.00750 .0050 .012] \mathrm{psu}$; and $S$ drift, [0.0055 0.0055

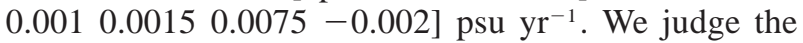
relative rms accuracy (over periods of days to a month) to be better than $0.005 \mathrm{psu}$, while absolute accuracy over the entire year is expected to be better than 0.01 psu.

\section{c. Mooring and section data scatter}

A comparison between the Seacat scatter over the first two weeks of deployment and the interior portion of the CTD section is shown in Fig. 5. The scatter seems much larger for the mooring, which led us to question the data initially. Yet histograms of the mooring data at each instrument (not shown) are very similar to histograms of the section data in a range about the instrument depths. The mooring histogram, however, has long, thin "tails" reflecting rare events with very anomalous properties, which are often seen to have vertical coherence across several instruments. The mooring and sections scatter, despite first appearances, thus seem to be consistent.

\section{REFERENCES}

Brickman, D., and D. E. Kelly, 1993: Development of convection in a rotating fluid: Scales and patterns of motion. Dyn. Atmos. Oceans, 19, 389-405. 
Bunker, A. F., 1976: Computations of surface energy flux and annual air-sea interaction cycles of the North Atlantic Ocean. Mon. Wea. Rev., 104, 1122-1140.

Clarke, R. A., and J.-C. Gascaard, 1983: The formation of Labrador Sea Water, Part I: Large-scale processes. J. Phys. Oceanogr., 13, 1764-1788.

Delworth, T., S. Manabe, and R. J. Stouffer, 1993: Interdecadal variations of the thermohaline circulation in a coupled ocean-atmosphere mode. J. Climate, 6, 1993-2011.

Dickson, R. R., and J. Brown, 1994: The production of North Atlantic Deep Water: Sources, rates and pathways. J. Geophys. Res., 99(C6), 12 319-12 341.

— J. R. N. Lazier, J. Meincke, P. Rhines, and J. Swift, 1996: Longterm coordinated changes in the convective activity of the North Atlantic. Progress in Oceanography, Vol. 38, Pergamon, 241295.

Fischer, J., and M. Visbeck, 1993: Seasonal variations of the daily zooplankton migration in the Greenland Sea. Deep-Sea Res., 40, $1547-1557$.

Gill, A. E., 1982: Atmosphere-Ocean Dynamics. Academic Press, 582-590.

Grant, A. B., 1968: Atlas of Oceanographic Sections. Temperaturesalinity-dissolved oxygen-silica, Davis Strait-Labrador BasinDenmark Strait-Newfoundland Basin. A.O.L. Rep. 68-5, 80 pp. [Available from the Atlantic Oceanographic Laboratory, Bedford Institute of Oceanography, Dartmouth NS B2Y 4A2, Canada.]

Hallberg, R. W., and P. B. Rhines, 1996: Buoyancy-driven circulation in an ocean basin with isopycnals intersecting the sloping boundary. J. Phys. Oceanogr., 26, 913-940.

Ivers, W. D., 1975: The deep circulation in the northern North Atlantic, with especial reference to the Labrador Sea. Ph.D. dissertation, University of California, San Diego, 179 pp.

Jones, H., and J. Marshall, 1993: Convection with rotation in a neutral ocean: a study of open-ocean deep convection. J. Phys. Ocean$o g r ., 23,1009-1039$.

Lazier, J. R. N., 1973: The renewal of Labrador Sea Water. DeepSea Res., 20, 341-353.

- 1980: Oceanographic conditions at Ocean Weather Ship Bravo. Atmos.-Ocean, 18, 227-238.

—, and D. G. Wright, 1993: Annual velocity variations in the Labrador Current. J. Phys. Oceanogr., 23, 660-678.

- P. B. Rhines, and R. W. Hallberg, 1997: The history of Labrador Sea Water properties through the 20th Century. Preprints.

Lee, T. N, W. Johns, F. Schott, and R. Zantopp, 1990: Western boundary current structure and variability east of Abaco, Bahamas at $26.5^{\circ}$ N. J. Phys. Oceanogr., 20, 446-466.

Legg, S., and J. Marshall, 1993: A heton model of the spreading phase of open-ocean deep convection. J. Phys. Oceanogr., 23, 1041-1056.

Lemon, D. D., D. M. Farmer, and D. R. Watts, 1984: Acoustic measurements of wind speed and precipitation over a continental shelf. J. Geophys. Res., 89(C3), 3462-3472.

Maxworthy, T., and S. Narimousa, 1994: Unsteady, turbulent convection into an homogeneous, rotating fluid, with oceanographic applications. J. Phys. Oceanogr., 24, 865-887.

McCartney, M., 1992: Recirculating components of the deep boundary current of the northern North Atlantic. Progress in Oceanography, Vol. 29, Pergamon, 283-383.
McWilliams, J. C., 1985: Submesoscale, coherent vortices in the ocean. Rev. Geophys., 23(2), 165-182.

- 1988: Vortex generation through balanced adjustment. J. Phys. Oceanogr., 18, 1178-1192.

Narimousa, S., 1998: Turbulent convection into a linearly stratified fluid: The generation of subsurface anticyclones. J. Fluid Mech., 354, 101-121

Pickart, R. S., W. M. Smethie Jr., J. R. N. Lazier, E. P. Jones, and W. J. Jenkins, 1996: Eddies of newly formed upper Labrador Sea Water. J. Geophys. Res., 101, 20 711-20 726.

— M. A. Spall, and J. R. N. Lazier, 1997: Mid-depth ventilation in the western boundary current system of the sub-polar gyre. Deep-Sea Res., Part 1, 44, 1025-1054.

Plueddemann, A. J., R. A. Weller, M. Stramska, and T. D. Dickey, 1995: Vertical structure of the upper ocean during the Marine Light-Mixed Layers experiment. J. Geophys. Res., 100(C4), 6605-6619.

Rhines, P. B., 1977: The dynamics of unsteady currents. The Sea, E. Goldberg, Ed., Wiley-Interscience, 189-319.

- 1994: Climate change in the Labrador Sea, its convection and circulation. Atlantic Climate Change Program: Proceedings of the PI's Meeting, A. M. Wilburn, Ed., University Corporation for Atmospheric Research, 85-96.

- 1998: Circulation, convection, and mixing in rotating, stratified basins with sloping topography. Physical Processes in Lakes and Oceans, J. Imberger, Ed., AGU Coastal and Estuarine Series, Vol. 54, 435-451.

—_, and J. R. N. Lazier, 1995: A 13-year record of convection and climate change in the deep Labrador Sea. Atlantic Climate Change Program: Proceedings of the PI's Meeting, A. M. Wilburn, Ed., University Corporation for Atmospheric Research, $57-64$.

Schott, F., and K. Leaman, 1991: Observations with moored acoustic doppler current profilers in the convection regime in the Golfe du Lion. J. Phys. Oceanogr., 21, 558-574.

—, M. Visbeck, and J. Fischer, 1993: Observations of vertical currents and convection in the central Greenland Sea during the winter of 1988/89. J. Geophys. Res., 98 (C8), 14 401-14 421. _ - - and U. Send, 1994: Open ocean convection, Mediterranean and Greenland Seas. Ocean Processes in Climate Dynamics: Global and Mediterranean Examples, P. Malanotte-Rizzoli, Ed., Kluwer, 203-225.

,,-- J. Fischer, L. Stramma, and Y. Desaubies, 1996: Observations of deep convection in the Gulf of Lions, northern Mediterranean, during the winter of 1991/92. J. Phys. Oceanogr., 26, 505-524.

Smith, S. D., and F. W. Dobson, 1984: The heat budget at Ocean Weather Station Bravo. Atmos.-Ocean, 22, 1-22.

Sy, A., M. Rhein, J. R. N. Lazier, K. P. Koltermann, J. Meincke, A. Putzkal, and M. Bersch, 1997: Surprisingly rapid spreading of newly formed intermediate waters across the North Atlantic Ocean. Nature, 386, 675-679.

Visbeck, M., and J. Fischer, 1995: Sea surface conditions remotely sensed by upward-looking ADCPs. J. Atmos. Oceanic Technol., 12, 141-149.

Worthington, L. V., and W. R. Wright, 1970: North Atlantic Ocean atlas of potential temperature and salinity in deep water, including temperature, salinity and oxygen profiles from the Erica Dan Cruise of 1962. The Woods Hole Oceanographic Institution Atlas Series, Folio 2, 58 plates, 24 pp. 